Published in final edited form as:

Sci Signal. ; 13(615): . doi:10.1126/scisignal.aay7315.

\title{
Spatial and temporal alterations in protein structure by EGF regulate cryptic cysteine oxidation
}

\author{
Jessica B. Behring $\%, 1$, Sjoerd van der Post ${ }^{\%, 1}$, Arshag D. Mooradian $\%, 1$, Matthew J. Egan ${ }^{1}$, \\ Maxwell I. Zimmerman ${ }^{2}$, Jenna L. Clements ${ }^{1}$, Gregory R. Bowman ${ }^{2}$, Jason M. Held ${ }^{1, \ddagger, \S}$ \\ ${ }^{1}$ Department of Medicine, Washington University School of Medicine in St. Louis, St. Louis, MO \\ 63110, USA \\ ${ }^{2}$ The Department of Biochemistry and Molecular Biophysics, Washington University School of \\ Medicine in St. Louis, St. Louis, MO 63110, USA
}

\section{Abstract}

Stimulation of plasma membrane receptor tyrosine kinases (RTKs), such as the epidermal growth factor receptor (EGFR), locally increases the abundance of reactive oxygen species (ROS). These ROS then oxidize cysteine residues in proteins to potentiate downstream signaling. Spatial confinement of ROS is an important regulatory mechanism of redox signaling that enables the stimulation of different RTKs to oxidize distinct sets of downstream proteins. To uncover additional mechanisms that specify cysteines that are redox-regulated by EGF stimulation, we performed time-resolved quantification of the EGF-dependent oxidation of 4200 cysteine sites in A431 cells. 51\% of cysteines were substantially oxidized by EGF stimulation. Furthermore, EGF induced three distinct spatiotemporal patterns of cysteine oxidation in functionally organized protein networks, consistent with the spatial confinement model. Unexpectedly, protein crystal structure analysis and molecular dynamics simulations indicated widespread redox regulation of cryptic cysteine residues that are solvent-exposed only upon changes in protein conformation. Phosphorylation and increased flux of nucleotide substrates served as two distinct modes by which EGF specified the cryptic cysteine residues that became solvent-exposed and redox-regulated.

\footnotetext{
*Corresponding Author, jheld@wustl.edu.

Author Contributions: J.M.H. designed the study. M.J.E., J.L.C, and J.M.H. carried out the experiments. J.B.B, S.V.D.P, A.D.M, M.I.Z, G.R.B, and J.M.H. performed data processing, analysis and interpretation. J.B.B., S.V.D.P., A.D.M., M.I.Z., J.L.C., G.R.B., and J.M.H. wrote the paper.

${ }^{\%}$ These authors contributed equally to this work.

\$Department of Anesthesiology, Washington University School of Medicine in St. Louis, St. Louis, MO 63110, USA

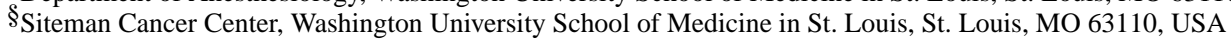

Editor's summary:

Uncovering cryptic cysteine residues for oxidation

Growth factor signaling results in the generation of reactive oxygen species (ROS) that oxidize cysteine residues in target proteins, triggering changes in activity, localization, or abundance. A longstanding question is how different growth factors specify the oxidation of cysteine residues in distinct subsets of proteins. Behring et al. found that many oxidized cysteine residues in target proteins were buried and not accessible under basal conditions. EGF stimulation altered the conformation of the target proteins through phosphorylation or nucleotide substrate flux, exposing the cryptic cysteine residues and enabling their oxidation. Thus, growth factor-mediated redox regulation of cysteine residues may be determined by changes in target protein conformation that occur in a pathway-specific manner.

Competing Interests: The authors declare that they have no competing interests.
}

Data and Materials Availability: The RAW and processed data associated with this manuscript have been deposited to the ProteomeXchange repository with the identifier PXD010880. All other data needed to evaluate the conclusions in the paper are present in the paper or the Supplementary Materials. 
Because proteins that are structurally regulated by different RTKs or cellular perturbations are largely unique, these findings suggest that solvent exposure and redox regulation of cryptic cysteine residues contextually delineates redox signaling networks.

\section{One-sentence summary:}

EGF-induced conformational changes enable the oxidation of cryptic cysteine residues in target proteins.

\section{Introduction}

Activation of many cell surface receptors transiently increase reactive oxygen species (ROS), predominantly hydrogen peroxide $\left(\mathrm{H}_{2} \mathrm{O}_{2}\right)(1-4)$, that act as important signaling second messengers. Growth factor-induced activation of receptor tyrosine kinases (RTKs) are the best studied examples and include epidermal growth factor (EGF) (1), insulin (5), platelet-derived growth factor (PDGF) (6), insulin-like growth factor-1 (IGF-1) (7), fibroblast growth factor (FGF) (8), and nerve growth factor (NGF) (9). However, cytokines (10-12), B- and T-cell receptors (13, 14), integrins (15), and G protein-coupled receptors (GPCRs) (16) are cell surface receptors that also increase ROS production upon activation. ROS-dependent cellular phenotypes are pleiotropic and include cell migration, proliferation, differentiation, polarization, and cell death (17).

Oxidation of cysteine residues is a key mechanism by which ROS transduce signaling changes. Oxidative inhibition of the catalytic cysteine residue of protein tyrosine phosphatases $(5,18,19)$ and, for EGF, redox regulation of EGFR itself $\beta$ ) functionally contributes to signaling. The factors that specify the cysteine residues that are oxidized by ROS produced in response to a stimulus are therefore the critical determinants regulating the specificity and crosstalk of redox signaling networks.

Spatial restriction of $\operatorname{ROS}(3,4,20-23)$ within subcellular microdomains $(20)$ is an important contributor determining which proteins and cysteine residues are oxidized. For EGF, the best studied redox signaling pathway, this occurs through localized activation of NADPH oxidases (NOX) and inactivation of peroxiredoxins (PRDXs) at the plasma membrane $3,4,20-23)$. Solvent accessibility and pKa of a cysteine residue are key determinants of its oxidizability, and EGF stimulation locally oxidizes solvent accessible catalytic cysteine residues with low pKa within endosomal microdomains in the canonical model $\beta, 4,20,21)$. Notably, the molecular details of cysteine oxidation upon EGF stimulation are static $\beta, 24)$ and it remains unknown how spatiotemporally dynamic cysteine redox is upon EGF stimulation. Elucidating the dynamic downstream redox control of proteins on a global scale at different points during the course of EGFR and NOX internalization and trafficking therefore requires a new approach (25).

Although spatial regulation is important to redox signaling, it is not the only factor that determines the cysteine residues that are oxidized by a stimulus $(4,26,27)$. For example, whereas EGF and insulin both generate NOX-derived ROS at the plasma membrane through activation of the RTKs EGFR and the insulin receptor, respectively, PTP1b is preferentially 
oxidized by insulin $\beta, 19)$. This differential redox sensitivity can be extended broadly because protein tyrosine phosphatases (PTPs) are redox regulated in distinct patterns upon stimulation by different RTKs and other cell surface receptors (4, 27-29). Because these stimuli are similarly spatially constrained at the cell surface, it is unclear how cysteine oxidation is specified by stimulus or context and how redox signaling pathways at the cell surface are discriminated from one another.

We therefore performed a workflow termed OxRAC (for cysteine oxidation analysis by resin-assisted capture) that advances existing redox proteomic workflows $\beta 0,31$ ) to characterize the dynamics of cysteine redox networks. OxRAC coupled enrichment of oxidized cysteine residues with high resolution, data-independent acquisition mass spectrometry analysis (DIA-MS) for comprehensive peptide quantitation. We quantified time-resolved changes in the oxidation state of 3,566 unique cysteine-containing peptides covering 4,200 cysteine sites at five timepoints after EGF stimulation in A431 cells, a common cellular model for EGF signaling studies $\beta, 24)$. We identified three cysteine redox networks with distinct spatiotemporal regulation and functional organization. Notably, protein structure analysis and molecular dynamics simulation revealed that cryptic cysteine residues (32), those that are solvent exposed only upon changes in protein conformation, were unexpectedly widespread and important contributors governing the specificity of redox signaling networks. EGFR-dependent phosphorylation and increased nucleotide substrate flux served as two distinct mechanisms by which EGF specified which cryptic cysteine residues were redox regulated.

\section{Results}

\section{The OxRAC workflow globally profiles dynamic changes in cysteine oxidation}

Serum-starved A431 cells were treated with EGF for 2 to 60 minutes before lysis in a degassed lysis buffer with N-ethylmaleimide (NEM) and sodium dodecyl sulfate (SDS) to fully denature proteins and block free thiols (Fig. 1A). This differential alkylation strategy is a common way to preserve the redox state of cysteine residues $(31,33)$ and facilitates timeresolved kinetic analysis. It also limits alterations in cell signaling that occur when cysteine sulfenic acids ( $\mathrm{SOH})$ are labeled in situ in cells with approaches previously used to investigate EGF-dependent cysteine oxidation $\beta, 24)$. Incubation with the SOH targeting probe DYn-2 (3), typical for EGF redox studies (24), altered EGF-dependent signaling on its own, significantly increasing phosphorylation of mitogen-activated protein kinase 3 (ERK) 3.5 fold (fig. S1). Rapid alkylation by NEM and inclusion of ethylenediaminetetraacetic acid (EDTA) in the lysis buffer minimizes non-specific oxidation $31,33,34)$, as demonstrated in this study by the low median percent oxidation of cytoplasmic proteins (11.6\%), which is consistent with previous reports (35). In addition, complete protein unfolding and alkylation by NEM was verified by Western blot (fig. S2A). For OxRAC analysis, samples were reduced and proteins with previously oxidized thiols were bound to thiopropyl sepharose resin 30,31$)$. Spike in of unlabeled synthetic cysteine-containing peptide was performed prior to binding followed by an isotope-encoded version after binding to normalize for differences in resin enrichment across samples (Fig. 1B). Proteins were digested on-resin, and peptides containing the previously oxidized cysteine residues were retained on the resin, 
eluted by reduction, alkylated with iodoacetamide (IAC), and analyzed by liquid chromatography-mass spectrometry (LC-MS) using both data-dependent acquisition (DDA) to identify peptides and data-independent acquisition mass spectrometry (DIA-MS) for quantitation using high resolution tandem mass spectrometry (MS2) chromatograms (Fig. 1B) (36). OxRAC enriched for analysis only the oxidized cysteine residues to increase coverage depth and incorporated DIA-MS analysis for high precision quantitation with limited to no missing data (37). This solved a limitation of isobaric tagging approaches for cysteine redox proteomics, which often have $25 \%$ or more data missing 38,39$)$ and thus have limited statistical power especially when multiple hypothesis correction appropriate for large proteomics datasets is considered.

Two control samples were processed and analyzed by LC-MS in parallel to confirm minimal false peptide identifications, remove background signal, and estimate the site occupancy of oxidation of each cysteine residue. Samples that were fully reduced and alkylated ("REDNEM") prior to digestion, resin binding, and IAC treatment served as a negative control. RED-NEM samples identified very few IAC modified peptides $(<0.05 \%)$ which confirmed minimal false peptide identifications (30), and exhibited minimal signal intensity by LC-MS (fig. S2B). This signal was subtracted from each peptide to remove background and improve quantitative accuracy. Samples reduced prior to thiopropyl sepharose ("RED") accounted for protein abundance and were used to estimate the oxidation stoichiometry of each cysteine residue.

DIA often differentiated which cysteine residue was oxidized in a peptide containing multiple cysteine residues (Fig. 1C). The extracted fragment ion chromatogram for the pyruvate kinase (PKM) peptide CCSGAIIVLTK with two adjacent cysteine residues demonstrated how this method distinguished peptide pairs (Fig. 1C). These cysteine residues were individually quantified using the $m / z$ of the $y 10$ fragment ion (red in Fig. 1C) as well as label-specific changes in relative hydrophobicity and retention times; NEM introduces a chiral center that resolves as peak doublets in reversed phase chromatography (40). Each singly oxidized cysteine residue in PKM exhibited a similar temporal response to EGF, yet only $\mathrm{Cys}^{424}$ was significantly redox regulated (Fig. 1D). The doubly oxidized Cys ${ }^{423}$, Cys ${ }^{424}$ peptide was also significantly oxidized, which peaked at 30 minutes after EGF stimulation (Fig. 1D). Additional examples of differentially regulated peptides with cysteine residues in close proximity were found in PLOD1, CTNND1, and DLD (Fig. 1E).

The redox status was quantified for 4,200 cysteine sites in 3,566 cysteine-containing peptides. $99 \%$ of cysteine residues were unambiguously assigned to a specific cysteine residue including $94.5 \%$ of peptides containing multiple cysteine residues. The functional annotation of almost $70 \%$ of the identified sites was unknown (Fig. 1F). Of those annotated in UniProt, 1205 sites participated in disulfide bonding, the majority of which were intramolecular (Fig. 1F).

\section{EGF-dependent regulation of cysteine redox networks cluster into three distinct temporal profiles associated with unique subcellular locations and biological processes}

To discern if there was time-dependent regulation of cysteine redox networks, the distribution of fold-changes compared to baseline at time 0 for all cysteine-containing 
peptides was examined (Fig. 2A). Widespread EGF-dependent oxidation was observed at 15 and 30 minutes, as indicated by right shifted, non-Gaussian distributions. To median-center and normalize these samples, Gaussian mixture modeling was used to best fit normal distributions to the data (Fig. 2A). They were then centered according to the median of the left-most distribution in each sample because EGF increases ROS production and cysteine oxidation $(1,3,41)$.

Notably, over half of the cysteine residues quantified (51.3\%) were significantly oxidized by EGF (Data File S1). Although high, the magnitude of oxidation of the cysteine redoxome was consistent with another study in which A431 cells were simulated with EGF (49\%,24)) as well as other endogenous perturbations, including $52 \%$ percent of cysteine residues oxidized by light-dark cycles 31 ) and $60 \%$ of cysteine residues oxidized upon fasting (42).

To characterize the kinetics of EGFR-dependent redox regulation of protein networks, we performed 3-component K-means clustering (Fig. 2B). Three distinct groups were observed without over-partitioning and most cysteine residues were maximally oxidized at 15-30 minutes, consistent with their non-normal fold-change distributions (Fig. 2A). The remaining peptides clustered either by peaking immediately at 2 minutes or having a delayed increase. We performed fuzzy c-means clustering to further define the temporal pattern of cysteine oxidation. Partitioning the data into 5 clusters indicated three unique temporal patterns of redox regulation (Fig. 2C), which we termed "signal initiators", "intermediate stimulators", and "terminal effectors" using previously coined, time-based descriptors of EGFR regulation (43). The "signal initiators" and "terminal effectors" appeared as separate clusters whereas "intermediate stimulators" encompassed the remaining 3 clusters, which we combined into a single representative cluster.

The biological roles of each of the three clusters were inferred with Gene Ontology (GO) enrichment analysis. Consistent with the prevailing model of localized ROS production by EGF, cysteine residues were regulated spatiotemporally, in concert with EGFR trafficking upon EGF stimulation. "Signal initiators" were associated with the cell periphery (Fig. 2C, Data File S2). "Intermediate stimulators" were enriched for metabolism, trafficking, protein glycosylation, and nucleotide processing as well as phosphatase and hypoxia inducible factor (HIF) signaling. "Terminal effectors" were involved in stress response, ROS metabolism, peroxiredoxin activity, calcium transport, and ER-nucleus signaling, which may indicate negative feedback. Surprisingly, EGF stimulation redox regulated many aspects of mitochondrial biology, including TCA and electron transport chain, mitochondrial fusion, and cardiolipin binding. Together, the data indicated that EGF regulates cysteine redox networks with three distinct temporal profiles that are associated with a wide range of biological processes.

\section{Cysteine residues in all major organelles are oxidized by EGF, but the location is influenced by temporal dynamics}

Prompted by the time-resolved regulation of spatially distinct subcellular compartments, we more systematically investigated the spatial regulation of EGF-dependent cysteine oxidation. Cytoplasmic and extracellular or luminal cysteine residues exhibited different temporal profiles of oxidation. Cytoplasmic cysteine residues peaked at 30 minutes and were less 
oxidized at 60 minutes whereas oxidation of extracellular and luminal localized cysteine residues was sustained over 60 minutes (Fig. 3A). Two cysteine residues in the cell surface receptor PLXNB2, Cys ${ }^{1484}$ and Cys ${ }^{937}$, localized to the cytoplasmic and extracellular sides of the cell, respectively, showed distinct patterns of redox regulation in which the extracellular cysteine residue was rapidly and transiently oxidized, similar to the "signal initiators" temporal pattern, and its intracellular cysteine residue was maximally oxidized at 15 and 30 minutes and returned to baseline at 60 minutes, similar to the "intermediate stimulators" temporal pattern (Fig. 3B). The redox regulation of intracellular and extracellular cysteine residues in EGFR showed similar kinetics (Data File S1).

To refine the characterization of redox localization to the organelle level, we assessed changes in cysteine oxidation of 943 "sentinel" proteins that were annotated in UniProt to a single subcellular compartment (Data File S1). EGF stimulation increased the percent of sentinel proteins oxidized in each of 10 cellular organelles, further establishing that EGFdependent redox regulation extends beyond plasma membrane microdomains (Fig. 3C). Sentinel proteins at the cell membrane were redox regulated most rapidly (Fig. 3C), consistent with GO annotations of "signal initiators".

Sentinel proteins in organelles with a predominantly reducing environment had a higher likelihood of being oxidized in response to EGF compared to those in oxidizing compartments (Fig. 3C). To determine if this was due to higher basal oxidation of cysteine residues in oxidizing compartments, limiting the potential for increased oxidation, we estimated the percent oxidation for peptides at baseline using samples prepared in parallel that were reduced before binding to thiopropyl sepharose to quantify total peptide levels in the sample. As expected, proteins in oxidized compartments were highly oxidized even at steady state, in contrast to those in reduced compartments (Fig. 3D). Notably, peroxisomes are major cellular sources of ROS and often considered an oxidizing environment; however, our analysis indicated that sentinel proteins in peroxisomes were both highly responsive to EGF-dependent ROS and had a basal oxidation percentage similar to those in reducing compartments (Fig. 3D). These results demonstrated that EGF redox regulates cysteine residuess in all major subcellular compartments but that the magnitude of oxidation increase is limited by the basal redox potential of each compartment.

Temporal patterns of cysteine redox regulation can distinguish specific redox processes and cysteine oxoforms. Extracellular cysteine residues are predominantly disulfide-linked, and upon EGF-induced internalization, they are reduced in endosomes (44). Most peptides annotated as 'disulfide' showed a unique temporal pattern (Fig 3E). Levels of singly oxidized peptides (1Ox) increased linearly together over the course of 60 minutes, along with a small decrease or no change in the level of the doubly oxidized (2Ox) peptides, consistent with internalization and partial reduction in endosomes throughout the time course. This pattern was unique and distinguishable from those annotated as active sites such as $\mathrm{Cys}^{80} / \mathrm{Cys}^{85}$ in DLD in which the oxidation of only one cysteine residue was specifically increased (Fig. 1E). These two regulatory hallmarks were observed for several nonannotated cysteine residues that group with known disulfide-linked cysteine residues, including Cys ${ }^{121 / 128}$ and Cys ${ }^{247 / 254}$ in TXNDC5 (Fig. 3F), suggesting that these were previously uncharacterized disulfide-linked cysteine residues. 


\section{Redox regulation of cysteine residues throughout canonical EGF signaling pathways is synchronized, peaking at 15 and $\mathbf{3 0}$ minutes}

Redox regulation of cysteine residues was prevalent in many members of canonical EGFdriven signaling pathways including matrix metalloproteinases, Rho family GTPases, and proteins involved in adherens junctions, protein translation, and proliferation (Fig. 4 and Data File S3). Components of caveolar-mediated endocytosis, which controls plasma membrane recycling and degradation of EGFR itself, were also redox regulated. Redox regulation was largely synchronous across most EGF-related pathways, peaking at 15-30 minutes after EGF stimulation which falls into the "intermediate stimulators" temporal pattern. Notably, caveolar-mediated endocytosis and matrix metalloproteinases were two pathways with a greater proportion of reduced cysteine residues, each of which include proteins that are endocytosed into the reducing environment of endosomes. In addition, the 31 unique peptides that were assigned to protein phosphatases and 44 unique peptide sequences assigned to kinases primarily fell into the "intermediate stimulators" temporal pattern and were maximally redox regulated at 15 and 30 minutes (fig. S3). This included catalytic cysteine residues in protein-tyrosine phosphatase 1B (PTP1B) 3,18 ) and low molecular weight phosphotyrosine protein phosphatase (ACP1), which can dephosphorylate phosphotyrosine residues in proteins (46).

\section{EGF stimulation targets unexpected protein domains for redox regulation}

Although canonical redox active protein domains were detected by OxRAC, many cysteine residues in these domains were not significantly redox regulated following EGF stimulation (Fig. 5A). The C-terminal domain of 1-cys peroxiredoxins ("1-cysPrx_C"), containing the resolving cysteine residue, were not redox regulated in response to EGF (Fig. 5A). Closer inspection of proteins containing the 1-cysPrx_C domain revealed that none of the resolving cysteine residues in PRDX1-4 were oxidized by EGF (Fig. 5B). Although the AhpC-TSA domain containing both the peroxidatic and allosteric regulator cysteine residues appeared to be EGF-regulated (Fig. 5A), this regulation was solely due to significant changes in oxidation of allosteric sites rather than the peroxidatic cysteine residue (Fig. 5B). Neither peroxidatic cysteine residues in PRDX5 or PRDX6 were significantly oxidized (Fig. 5B). However, unlike the canonically redox active cysteine residues, non-catalytic cysteine residues in PRDX1-4 exhibited up to a nearly 16-fold change in oxidation (Fig. 5B).

Other protein domains and families were hotspots for EGF-dependent redox regulation (Fig. 5A) including the RNA recognition motif (RRM_1), AAA ATPases, 14-3-3 proteins, small GTPases, and kinases. One example of pervasive EGF-dependent redox regulation throughout a protein family was AAA ATPases, which comprises 57 genes with very low cysteine sequence conservation that play a diverse role in cellular functions (fig. S4A). OxRAC profiling detected that 33 of 37 peptides assigned to ATPase family members were significantly oxidized by EGF (fig. S4A). One of these AAA ATPases, Valosin-containing protein (VCP), was the most oxidized protein in this study, with EGF-redox regulated cysteine residues throughout all of its domains (fig. S4B-D), including $\mathrm{Cys}^{522}$, which inhibits VCP function (47). Given that VCP plays a key role in resolving ER stress, and EGFR signaling is enhanced by ER stress (48), oxidative inactivation of VCP upon EGF stimulation may enhance EGFR signaling. 


\section{EGF stimulation redox regulates functionally relevant cysteine residues}

The EGFR signaling network is robust, parallelized, and pleiotropic, thus even canonical downstream regulators such as AKT and mammalian target of rapamycin (mTOR) are dispensable or limited contributors to EGF-induced phenotypes (49-51). Complex feedback loops compensate for loss of a single regulatory effector $(52,53)$, complicating the reductionist approach of site-directed mutagenesis, which is also not applicable to enzymes in which the cysteine residue is directly involved in their activity $(54,55)$. To our knowledge, no single point mutation of a posttranslational modification site of canonical downstream effectors substantially affects EGF-induced phenotypes.

Therefore, to delineate whether EGF-dependent redox regulation had an impact on protein function, we first examined if active sites or other functionally relevant cysteine residues were substantially oxidized by EGF treatment. These included the phosphatases ACP1 and PTP1B, which require their redox regulated active sites Cys ${ }^{13}$ (27) and Cys ${ }^{215}$ (56), respectively; caspases- 1 and -3 , which are inactivated by mutation of Cys ${ }^{215}$ (57) and Cys ${ }^{163}$ (58) respectively; glyceraldehyde 3-phosphate dehydrogenase (GAPDH), which requires Cys $^{152}$ (59); and ubiquitin thioesterase (OTUB1) which is catalytically inert when Cys ${ }^{91}$ is mutated (60). Furthermore, protein disulfide-isomerase (P4HB) is unable to bind a misfolded substrate upon mutation of the significantly redox regulated $\mathrm{Cys}^{397}$ and Cys ${ }^{400}$ (61) (Data File S1); cathepsin B is inactivated by mutation of the redox regulated Cys ${ }^{108}$ (62); UDP-glucose 6-dehydrogenase (UGDH) has negligible activity when the redox regulated $\mathrm{Cys}^{276}$ is mutated (63); VCP Cys ${ }^{522}$ is required for activity (47); and thioredoxin is unable to release substrates when the redox regulated $\mathrm{Cys}^{32}$ and $\mathrm{Cys}^{35}$ are mutated (64). In addition, the yeast homolog of Isopentenyl-diphosphate delta-isomerase 1 (IDI1) is much less catalytically active upon mutation of its redox regulated active site $\mathrm{Cys}^{86}$ (65).

We next investigated whether cysteine residues oxidized by EGF stimulation are allosteric regulators of protein function. AKT Cys ${ }^{296}$ was significantly oxidized by EGF treatment (Data File S1) and is an allosteric inhibitory site in AKT (66). Mutation of Cys ${ }^{183}$ in ERK, which was significantly oxidized (table S1), abrogates its phosphorylation and activity and decreases the antiapoptotic potential of ERK in response to nitrosative stress (26). Together, these findings verify that many cysteine residues oxidized by EGFR are functionally relevant. Notably, only $11 \%$ of the cysteine residues significantly oxidized following EGF stimulation were annotated in UniProt as an active site, disulfide bond, metal binding, or site of lipidation (Fig. 5C), indicating that many of the identified sites may have allosteric functions (Fig. 5D, filled grey circles).

\section{Redox-independent regulation of protein structure by EGF specifies cryptic cysteine residues for oxidation}

Both solvent accessibility and $\mathrm{pKa}$ are potential determinants of a cysteine cysteine residue's likelihood to be oxidized. Bioinformatic prediction using the surrounding amino acid sequence and available structural information (67) revealed that cysteine residues significantly redox regulated by EGF have no change in pKa (fig. S5). Furthermore, most of the oxidized cysteine residues had a low relative solvent accessibility (RSA), even slightly lower than those that were detected but not oxidized (Fig. 6, A and B). The median RSA of 
cysteine residues oxidized by EGF was 6\% (Fig. 6A), well below the threshold of $25 \%$ that is considered solvent accessible (67). This surprising observation is consistent with Yang et al. (24); evaluating their dataset with the same solvent prediction tool revealed that the cysteine targets of exogenous $\mathrm{H}_{2} \mathrm{O}_{2}$ were largely solvent accessible, as expected, but those targeted by EGF were largely solvent inaccessible (24) (Fig. 6C). The unexpected lack of solvent accessibility of EGF-dependent redox regulated cysteine residues led us to further investigate what governed their oxidation.

The 14-3-3 family consists of 7 highly conserved proteins that bind phospho-serine/ phospho-threonine motifs, interact with EGFR, and promote EGFR signaling $(68,69) .8$ of 9 peptides detected in 14-3-3 proteins were significantly oxidized by EGF, most notably oxidation of a highly conserved cysteine residue in helix 4 in five of the six 14-3-3 family members detected (Fig. 6, D and E). This helix 4 cysteine residue was one of the least solvent accessible amino acids in 14-3-3 proteins, as determined from crystal structures, and substitution to either alanine or serine destabilizes the protein (70). Consistent redox regulation of this buried cysteine residue across nearly all 14-3-3 proteins verified that highly solvent inaccessible cryptic cysteine residues (44) were bona fide hotspots for EGFdependent redox regulation.

We therefore hypothesized that redox-independent regulation of protein conformation as a consequence of EGF stimulation may solvent expose cryptic cysteine residues for oxidization and provide context-dependence. One potential mechanism by which EGF may induce conformational changes is protein phosphorylation. Cys ${ }^{65}$ in ERK was significantly oxidized by EGF ( 1.96-fold at $30 \mathrm{~min}$ ), but was solvent inaccessible in the unmodified ERK crystal structure with an RSA of $4.2 \%$ (Fig. 6F). However, the crystal structure of mitogen-activated protein kinase 1 (ERK2) phosphorylated at $\mathrm{Thr}^{183}$ and $\operatorname{Tyr}^{185}$, a consequence of EGF stimulation 71,72 ), showed that Cys ${ }^{65}$ becomes solvent exposed (Fig. $6 \mathrm{~F}$, blue sphere indicates solvent). Mutation of this cysteine residue confers a level of resistance to ERK inhibitors, with one study suggesting that site may be close enough in proximity to affect the ATP binding pocket targeted by these drugs (73).

Many members of the small GTPases family play a role in EGFR signaling. OxRAC profiling identified 20 peptides, assigned to 18 genes, in the small GTPase family that were significantly oxidized by EGF. Many diverse small GTPase family members were significantly oxidized, though the closely related RHO, RAC, and cell division control protein 42 (CDC42) proteins, which play a role in EGFR-dependent endocytosis, invasion, and metastasis, were preferentially targeted (fig. S4E). These results indicated that the small GTPase family is far more redox-sensitive than previously described (74). Examination of crystal structures for CDC42 and Rac1 showed that the thiol of the cryptic cysteine residues oxidized by EGF (Cys ${ }^{157}$ in each protein, RSAs of 2.5 and $2.6 \%$, respectively) exists at the base of a solvent accessible pocket that is blocked by a nucleotide ligand (Fig. 6G, yellow sticks). Because EGF increases the GTPase activity of these proteins (75), increased nucleotide exchange would enable $\mathrm{H}_{2} \mathrm{O}_{2}$ to oxidize the cysteine residue. Therefore EGFdependent changes in enzyme activity was an additional mechanism by which EGFdependent stimulation could specify the cryptic cysteine residues that were redox regulated. 
Analysis of VCP crystal structures further validated EGF-dependent oxidation of cryptic cysteines. $\mathrm{Cys}^{77}$ in VCP, which was significantly oxidized (fig. S4B), is solvent accessible in the ATPYS bound structure but solvent inaccessible in the ADP bound state (fig. S4C). Another cysteine residue in VCP, $\mathrm{Cys}^{209}$, was significantly oxidized by EGF stimulation and lies at the base of the nucleotide ligand pocket, similar to GTPases, and would be solvent accessible during turnover (fig. S4D). Together, cryptic cysteine residues in multiple proteins were oxidized by EGF because of structural changes induced by phosphorylation, activity, and nucleotide flux.

There are only limited examples of phosphoprotein crystal structures, and crystal structures are biased towards low energy conformers and do not accurately convey all the structural ensembles of a protein (76). The GTPase KRAS is activated by EGF and transduces signaling to ERK, but EGF only increased the oxidation of solvent inaccessible $\mathrm{Cys}^{80}$ rather than solvent accessible Cys ${ }^{118}$ in KRAS (Fig. $6 \mathrm{H}$, table $\mathrm{S} 1$ ) which is redox regulated (77). To find evidence of cryptic pockets in KRAS that expose cryptic cysteine residues, we characterized its protein conformational ensembles with the fluctuation amplification of specific traits algorithm (FAST) to observe transitions between states that are inaccessible to conventional molecular dynamics (MD) $(78,79) . \mathrm{Cys}^{80}$ had an exposed solvent accessible surface area (80) in approximately $4 \%$ of the states, which arose from a cryptic pocket opening between helices 2 and 3 (representative conformation shown in Fig. 6H). This transient solvent exposure of a cryptic, buried cysteine residue provided a potential mechanism by which redox reactions could occur, supporting the plausibility of the widespread redox regulation of cryptic cysteine residues we observed.

\section{Discussion}

The EGF pathway is an intensively characterized and modeled signaling network due to its importance in migration, differentiation, and cancer $24,43,81-84)$. However, our current understanding of the dynamics and specificity of cysteine redox regulation is limited compared to the extensively characterized phosphorylation, acetylation, ubiquitination and interactome changes stimulated by EGF treatment of A431 cells $(43,81,82,84,85)$. We therefore quantified redox regulation of the cysteine redoxome at a systems level with OxRAC to address three major questions. Is redox regulation by EGF stimulation confined to endosomal microdomains? What specifies the cysteine residues that are oxidized upon stimulation with EGF, but not with other stimuli with similar spatial redox regulation such as other growth factors? What is the temporal correlation and interplay between downstream cysteine oxidation and phosphorylation?

A total of 3,566 unique cysteine-containing peptides spanning 4,200 cysteine sites were quantified by OxRAC for three biological replicates at each of six timepoints. The high depth of coverage was evidenced by the detection of low-abundant proteins such as the tumor suppressor p53, which previously required targeted MS analysis for detection (33), and included many functionally relevant cysteine residues in this protein. EGF stimulation significantly oxidized more than half of the peptides in our dataset (51.3\%), a percentage on par with increased sulfenation of $49 \%$ of cysteine residues upon EGF stimulation (24) and other physiological stimuli that oxidize nearly half of the cysteine residues detected $(31,42)$. 
EGF stimulation induced clear spatiotemporal regulation of cysteine redox networks. Three temporal patterns of cysteine redox regulation were identified, each with unique biological and functional organization. These were located throughout all major cellular organelles, demonstrating that EGF-dependent redox signaling was not confined to endosomal microdomains. Several possibilities can explain the unexpectedly broad spatial distribution of oxidized cysteine residues. One is that ROS diffuse further into the cell than previously thought $(4,20)$ and that localized microdomains of ROS-such as those in the nucleus that emerge through phosphorylation-mediated inhibition of PRDX1 near the centrosome (21) occur throughout the cell to facilitate cysteine oxidation. Second, redox active endosomes may translocate throughout the cell. Third, direct oxidation of cysteine residues by ROS may occur proximal to redox active endosomes, but disulfide-relays, EGF-dependent changes in the redox potential of an organelle or translocation of a protein from one redox environment to another expand the reach of cysteine oxidation throughout the cell.

Endogenous oxidation by EGF induced widespread oxidation of cryptic cysteine residues. Although high solvent accessibility is generally agreed to be an essential feature of oxidizable cysteine residues (86), these results support an emerging regulatory model of redox signaling in which redox-independent changes in protein structure and activity, resulting from specific stimuli such as EGF, specify the cysteine residues that are oxidized by changing solvent accessibility 32,87$)$. Our observation of widespread redox regulation of cryptic cysteine residues was consistent with Gould et al., who observed that cysteine residues that are oxidized under basal conditions in mouse liver are primarily buried (88); Alegre-Cebollada et al. (32), who identified glutathionylation of cysteine residues in titin upon unfolding; and Yang et al. (24), who found that although the sulfenated targets of $\mathrm{H}_{2} \mathrm{O}_{2}$ were largely solvent accessible, the cysteine targets sulfenated by EGF have a median surface accessibility of only $16 \%$-well below the accessible cutoff of $25 \%$ (67). Our structural analysis of EGF, KRAS, and VCP suggested at least two possible mechanisms by which EGF stimulation could regulate the solvent accessibility of redox regulated cryptic cysteine residues: Phosphorylation and GTP/GDP cycling. Together, these results indicate that EGF-dependent, redox-independent conformational regulation of cryptic allosteric cysteine residues is a widespread mechanism that confers context-dependent selectivity in redox signaling networks.

EGF-dependent phosphorylation is a potential mechanism to specify certain cryptic cysteine residues, and this occurs prior to and concomitant with bulk redox regulation. We observed that the majority of cysteine residues fall into the "intermediate stimulators" temporal pattern, and are oxidized 15 and 30 minutes after EGF stimulation, with kinetics similar to those reported for phosphorylation of serine and threonine residues, but substantially delayed from phospho-tyrosine signaling which peaks at $\sim 1$ minute post-EGF stimulation but is sustained $(43,45)$. The differential solvent accessibility of Cys ${ }^{65}$ in ERK2 exemplifies how redox-independent phosphorylation can precede and specify a cryptic cysteine residue for oxidation. The majority of cysteine redox regulation at 15 and 30 minutes is also slightly delayed from the previously observed kinetics of peak ROS production and cysteine sulfenation after EGF stimulation, which occurs in the first 5-15 minutes $3,43,45,89)$. Our kinetic profiling suggests that downstream, more stable disulfide bonds or glutathionylated cysteine residues are primarily detected by OxRAC and persist beyond the initial burst of 
ROS production. Because changes in protein structure regulate glutathionylation of specific cysteine residues in titin (32), our results support a model in which endogenous redox signaling networks are predominantly specified by prior changes in protein structure.

Our results demonstrate that non-catalytic cysteine residues in PRDXs are dynamically oxidized upon EGFR signaling. We did not observe an increase in oxidation of the peroxidatic cysteine residues in PRDX5 and PRDX6 or resolving cysteine residues in PRDX1-4, but were unable to detect oxidation of the peroxidatic cysteine residues in PRDX1-4, similar to a previous report (24). In contrast, we observed that non-catalytic sites in PRDXs were highly redox regulated which suggests that their role in non-canonical disulfide linked heterodimeric relays with other proteins (90) may be widespread.

The singularly unique connections of the cysteine redoxome to cellular redox networks, coupled with the ability to assess or infer the position of the regulated cysteine residue in protein structure, subcellular location, and function, can be leveraged to provide an integrative portrait of cellular redox regulation (25). OxRAC analysis and cysteine redox proteomics can profile the system-wide dynamics of redox regulation in time and space, integrate information about redox regulation mediated directly by and independently of ROS, and uniquely profile context-dependent redox regulation due to changes in protein conformation and activity. This work provides a database of potentially druggable cysteine residues (91), including many cryptic cysteine residues not previously expected to be oxidized by EGF, and shifts the paradigm of what governs specificity in redox signaling networks. In addition, because many proteins canonically downstream of EGFR are redox regulated, these results offer new avenues for integrating redox signaling into current therapeutic interventions.

\section{Materials \& Methods}

\section{Materials}

All materials are from Sigma unless otherwise noted.

\section{Cell culture and treatments}

A431 cells were maintained at $37^{\circ} \mathrm{C}, 5 \% \mathrm{CO}_{2}$, in Dulbecco's Modified Eagle Medium (DMEM) with $4.5 \mathrm{~g} / \mathrm{L}$ glucose, $1 \mathrm{mM}$ pyruvate and $10 \%$ fetal bovine serum (Gibco). 2e6 cells were plated in $10 \mathrm{~cm}$ dishes, grown for 3 days, then serum starved overnight after three washes (5 min each) with serum free DMEM. Zero time points as well as samples that would be fully reduced or fully alkylated as positive and negative controls, respectively, were not treated with EGF. For all others, human recombinant EGF protein (R\&D Systems) was diluted to 10x in serum free DMEM, added to each dish (final concentration of 100 $\mathrm{ng} / \mathrm{mL})$ and swirled. After the appropriate incubation time $(2,5,15,30$, or $60 \mathrm{~min})$, media was aspirated and lysis buffer added.

\section{Differential thiol alkylation}

Cells were lysed in $500 \mu \mathrm{L}$ degassed, fully denaturing lysis buffer (3\% SDS, 10mM EDTA, 200mM Tris pH 7.0, $100 \mathrm{mM}$ NEM except for the Reduced and Reduced+NEM samples 
that were lysed without NEM but in the presence of $11 \mathrm{mM}$ tris(2-carboxyethyl)phosphine (TCEP) to reduce). Proteins in Reduced samples are unblocked and therefore all can bind to thiopropyl sepharose, whereas cysteine residues in Reduced + NEM lysates are full alkylated (fig. S2) and are only bound and detected due to non-specific binding. Lysates were probe sonicated briefly then incubated at $37 \mathrm{C}$ for $45 \mathrm{~min}$ at $950 \mathrm{rpm}$ to alkylate. For the RED+NEM samples, lysates were reduced at $50 \mathrm{C}$ for $45 \mathrm{~min}$ followed by addition of $100 \mathrm{mM}$ NEM at $37 \mathrm{C}$ for $45 \mathrm{~min}$. All samples were quenched after NEM incubation with $133 \mathrm{mM}$ cysteine ( $60 \mathrm{~min}, 37 \mathrm{C}, 950 \mathrm{rpm}$ ). All samples were then reduced with $11 \mathrm{mM}$ TCEP (45 min, $50 \mathrm{C}, 950 \mathrm{rpm}$ ) and precipitated with 4 volumes of methanol overnight at $-80 \mathrm{C}$.

\section{In situ dyn-2 treatment and Western blots}

A431 cells were grown and serum starved as for EGF treatment and OxRAC prior to addition of $5 \mathrm{mM}$ DYn-2 (Acme Bioscience) or vehicle, $1 \%$ dimethyl sulfoxide (DMSO), for $1 \mathrm{hr}$. Cells were lysed in 3\% SDS, $25 \mathrm{mM}$ Tris pH 7.4 and assayed by Western blot. Membranes were hybridized with the following primary antibodies diluted at 1:1000 in 5\% bovine serum abumin (Thermo) + Tris-buffered Saline Tween (TBS-T): ERK, phospho-ERK $\mathrm{Thr}^{202} / \mathrm{Tyr}^{204}$, AKT, phospho-AKT (Ser ${ }^{473}$ ), Vinucullin (Cell Signaling), or panphosphotyrosine (Millipore). Densitometry was performed with Image J.

\section{Preparing thiopropyl sepharose 6B}

$20 \mathrm{mg}$ Thiopropyl sepharose 6B resin (GE Life Science) per sample was washed with $1 \mathrm{~mL}$ degassed water for $15 \mathrm{~min}$ to rehydrate at room temperature. The resin was centrifuged $(1000 \mathrm{x} \mathrm{g}, 30 \mathrm{sec})$ and the supernatant was removed. $1 \mathrm{~mL}$ water was added to wash resin, the resin was centrifuged $(1000 \mathrm{xg}, 30 \mathrm{sec})$ and washed again with $1 \mathrm{~mL}$ water. All buffers used for thiopropyl sepharose steps were freshly degassed with sonication in a water bath for at least $30 \mathrm{~min}$. This process was repeated twice more, but the sepharose was washed with thiopropyl sepharose binding buffer (6 M guanidine $\mathrm{HCl}, 0.1 \% \mathrm{NP}-40,25 \mathrm{mM}$ Tris $\mathrm{pH} 7.4$, $150 \mathrm{mM} \mathrm{NaCl}, 5 \mathrm{mM}$ EDTA). Buffer was aspirated prior to addition of protein lysates.

\section{Thiopropyl sepharose 6B binding}

Precipitated proteins were centrifuged (1,500 x g, $5 \mathrm{~min})$ and the supernatant was removed. Pellets were washed with $1 \mathrm{~mL} 80 \%$ methanol three times by resuspending the pellet and centrifuging it each time. Samples were resuspended in $800 \mu \mathrm{L}$ thiopropyl sepharose binding buffer (6 M guanidine $\mathrm{HCl}, 0.1 \% \mathrm{NP}-40,25 \mathrm{mM}$ Tris $\mathrm{pH}$ 7.4, $150 \mathrm{mM} \mathrm{NaCl}, 5 \mathrm{mM}$ EDTA) using sonication and vortexing. 4 pmol unlabeled CysOx Peptide Standard (VSAPGAGSAKADTGPACGTAR, custom synthesized by ThermoFisher) was added to each sample for normalization. This synthetic peptide has a non-human sequence and contains a cysteine residue to bind to the resin and an internal lysine that is cleaved by trypsin and released, enabling normalization during sample processing. Lysates were added to thiopropyl sepharose resin and incubated in the dark at $4 \mathrm{C}$ rotating end-over-end. 


\section{Thiopropyl sepharose 6B washing and elution}

All buffers were degassed prior to use and all washes were $500 \mathrm{uL}$, rotating end over end, for $10 \mathrm{~min}$ at room temperature. Lysates plus resin were transferred to spin columns (Sigma) and centrifuged to remove unbound protein. The resin was washed three times with thiopropyl sepharose binding buffer, three times with quantitative cysteinyl-peptide enrichment technology (QCET) buffer (50 mM Tris pH 8.0 plus $1 \mathrm{mM}$ EDTA), 4 times with SDS/NP-40 buffer (1\% NP-40, 0.1\% SDS, 5mM EDTA, $150 \mathrm{mM} \mathrm{NaCl,} 25 \mathrm{mM}$ Tris $\mathrm{pH}$ 7.4), 4 times with $80 \%$ acetonitrile, and 4 times with high salt buffer $(2 \mathrm{M} \mathrm{NaCl}, 50 \mathrm{mM}$ Tris $\mathrm{pH} 7.4)$.

To prepare for trypsin digestion, the resin was briefly washed with $800 \mathrm{uL}$ trypsin digestion buffer (1 M urea, $50 \mathrm{mM}$ Tris $\mathrm{pH} 8.0$ ) as above. 4 pmol of stable isotope labeled CysOx Peptide The standard VSAPGAGSAKADTGPACGTAR $\left[{ }^{13} \mathrm{C}_{6},{ }^{15} \mathrm{~N}_{2}\right.$ labeled lysine, and ${ }^{13} \mathrm{C}_{6},{ }^{15} \mathrm{~N}_{4}$ labeled arginine, custom synthesized by ThermoFisher) was added to each sample for normalization. $4 \mu \mathrm{g}$ sequencing grade trypsin (Roche) was dissolved in $165 \mu \mathrm{L}$ ice cold trypsin digestion buffer and added to resin in the spin columns with the bottom capped. Digestion proceeded overnight at $37 \mathrm{C}, 950 \mathrm{rpm}$. Spin columns were centrifuged to elute non-bound peptides, which contained non-oxidized peptides in proteins with an oxidized cysteine residue. Resin was washed three times with a wash buffer (6 M guanidine $\mathrm{HCl}, 5 \mathrm{mM}$ EDTA, $150 \mathrm{mM} \mathrm{NaCl}, 25 \mathrm{mM}$ Tris $\mathrm{pH}$ 7.4), five times with high salt buffer, 3 times with $80 \%$ acetonitrile, and 3 times with QCET buffer.

Peptides were eluted with $100 \mu \mathrm{L} 20 \mathrm{mM}$ dithiothreitol (DTT) in QCET buffer by capping the bottom of the spin column and incubating the lysate at $60 \mathrm{C}, 900 \mathrm{rpm}$, for $10 \mathrm{~min}$. Samples were centrifuged (1,500 x g, $1 \mathrm{~min})$ to collect eluent, and elution was repeated 2 additional times for $10 \mathrm{~min}$ each. $100 \mu \mathrm{L} 80 \%$ acetonitrile was used as a final elution. 150 $\mu \mathrm{L}$ of $100 \mathrm{mM}$ iodoacetamide in QCET buffer was added to eluents, which were incubated in the dark for $45 \mathrm{~min}$ at room temperature and were quenched by addition of $3 \mu \mathrm{L} 1 \mathrm{M}$ cysteine in QCET buffer for $30 \mathrm{~min}$ at room temperature. 0.5\% formic acid (final volume) was added, vacuum centrifuged to near dryness, acidified with $0.5 \%$ formic acid and desalted using HLB Oasis SPE cartridges (Waters) as previously described(92). Eluted samples were concentrated to near dryness in a vacuum centrifuge and resuspended in $0.5 \%$ formic acid for LC-MS.

\section{LC-MS}

Samples were analyzed by reverse-phase HPLC-MS/MS using a nano-LC 2D HPLC system (Eksigent) which was directly connected to a quadrupole time-of-flight (QqTOF) TripleTOF 5600 mass spectrometer (AB SCIEX) in direct injection mode. The controls, RED and REDNEM, were analyzed separately. $3 \mu \mathrm{L}$ of analyte was loaded onto a $3 \mu \mathrm{l}$ sample loop. After injection, peptide mixtures were transferred onto a self-packed (ReproSil-Pur C18-AQ, 3 $\mu \mathrm{m}$, Dr. Maisch, Germany) nanocapillary HPLC column (75 $\mu \mathrm{m}$ I.D. x $22 \mathrm{~cm}$ column) and eluted at a flow rate of $250 \mathrm{~nL} / \mathrm{min}$ using the following gradient: $2 \%$ solvent $\mathrm{B}$ in $\mathrm{A}$ (from 0-7 min), 2-5\% solvent B in A (from 7.1 min), 5-30\% solvent B in A (from 7.1-130 min), $30-80 \%$ solvent B in A (from 130-145 min), isocratic 80\% solvent B in A (from 145-149 $\mathrm{min}$ ) and $80-2 \%$ solvent $\mathrm{B}$ in A (from 149-150 min), with a total runtime of $180 \mathrm{~min}$ 
including mobile phase equilibration. Solvents were prepared as follows: mobile phase A, $0.1 \%$ formic acid (v/v) in water, and mobile phase B, $0.1 \%$ formic acid (v/v) in acetonitrile. Mass spectra were recorded in positive-ion mode. After acquisition of 1-3 samples, MS spectra and MS/MS spectra were automatically calibrated using beta-galactosidase (AB SCIEX). Two different mass spectrometric acquisition workflows were performed in this study. The first was data-dependent acquisitions (DDA). For collision induced dissociation tandem mass spectrometry (CID-MS2), the mass window for precursor ion selection of the quadrupole mass analyzer was set to $\pm 0.7 \mathrm{~m} / \mathrm{z}$. MS1 scans ranged from $380-1250 \mathrm{~m} / \mathrm{z}$ at a resolution of 30,000 with an accumulation time of $250 \mathrm{~ms}$. DDA was used for MS2 (MS/MS) collection on the TripleTOF 5600 at a resolution of 15,000 to obtain MS2 spectra for the 50 most abundant parent ions following each survey MS1 scan. Dynamic exclusion features were based on value $\mathrm{MH}^{+}$not $\mathrm{m} / \mathrm{z}$ and were set to an exclusion mass width $50 \mathrm{mDa}$ and an exclusion duration of $30 \mathrm{sec}$. MS2 scans ranged from 100-1500 $\mathrm{m} / \mathrm{z}$ with an accumulation time of $50 \mathrm{msec}$. The second workflow was data-independent MS2 acquisitions (DIA). In the 'SWATH' DIA MS2 acquisition, instead of the Q1 quadrupole transmitting a narrow mass range through to the collision cell, a wider window of $\sim 10 \mathrm{~m} / \mathrm{z}$ is passed in incremental steps over the full mass range $(\mathrm{m} / \mathrm{z} 400-1250$ with $85 \mathrm{SWATH}$ segments, $63 \mathrm{msec}$ accumulation time each, yielding a cycle time of $5.5 \mathrm{sec}$ which includes one MS1 scan with $50 \mathrm{msec}$ accumulation time). SWATH MS2 produces complex MS/MS spectra that are a composite of all the analytes within each selected Q1 $\mathrm{m} / \mathrm{z}$ window.

\section{Bioinformatic database searches for TripleTOF 5600}

Mass spectral data sets were analyzed and searched with both MaxQuant(93)(version 1.5.3.30) and Mascot (Version 2.5.1, Matrix Science) against the UniProt Human reference proteome. MaxQuant search parameters included: First peptide search tolerance of 0.07 Da and main peptide search tolerance of $0.0006 \mathrm{Da}$, and variable methionine oxidation, protein $\mathrm{N}$-terminal acetylation, carbamidomethyl, and NEM modifications with a maximum of 5 modifications per peptide, 2 missed cleavages and trypsin/P protease specificity. Razor protein false discovery rate (FDR) was utilized and the maximum expectation value for accepting individual peptides was 0.01 (1\% FDR) and a minimum score for modified peptides of 25. For all Mascot searches, parameters were the same except for mass tolerance of $25 \mathrm{ppm}$ and 0.1 Da for MS1 and MS2 spectra, respectively, and decoy searches were performed choosing the Decoy checkbox within the search engine. For all further data processing, peptide expectation values were filtered to keep the FDR rate at $1 \%$.

\section{Skyline Data Analysis}

Skyline software (94) was used to manually examine and quantify DIA data. Spectral libraries were generated in Skyline using the DDA database searches of the raw data files. Raw files were directly imported into Skyline in their native file format, and only cysteinecontaining peptides were quantified.

\section{Data processing}

Each run was normalized for loading by dividing all raw intensities by the respective run's light peptide raw intensity. DIA runs for each sample were averaged then every peptide modified sequence was background-subtracted by subtracting the respective peptide's bio- 
rep average for RED+NEM. Any data points below background were considered to be zero. In the case of multiple charge states for a single peptide modified sequence, values were summed. Values from peptides with missed cleavages were also summed if the missed cleavage peptide did not span any additional cysteine residues and matched to the same exact gene product(s) as the fully cleaved peptide. To calculate fold-change, the derived values from each of 3 individual biological replicates at 2, 5, 15, 30, and 60 min were divided by the average of the zero-time-point. These were $\log _{2}$ transformed and the ratios were carried forward for further analysis.

\section{Estimating site occupancy of oxidation}

Following loading normalization and background subtraction from the RED-NEM samples, sample signal intensities for each oxidized peptide were divided by the reduced 'RED' signal intensity. The RED samples estimate the total amount of each peptide (free and reversibly oxidized forms) in the cells. Outliers with a Z-score $>|2|$ were removed and the highest and lowest percent oxidation was rescaled and confined to $0-100 \%$ using a similar approach as previous studies $(83,95-97)$. Approaches using differential alkylation cannot detect sulfinic and sulfonic acid because they are not reducible, thus the site occupancy determination is an estimate though increased occupancy may lead to increased likelihood of biological consequence $33,95,98)$.

\section{Fitting normal distributions for re-normalization of relative expression changes}

Gaussian mixture models were made using the GaussianMixture function from the scikitlearn package (v.0.19.1) in Python (v.3.6). Diagonal covariance matrices were used to constrain the models, and a maximum of 100 iterations were used for fitting. For timepoints at 2, 5, and $60 \mathrm{~min}$ of EGF treatment, the data from each replicate were modeled and centered using one component. For the 15 and 30 min timepoints, three components were used to identify Gaussian subpopulations, and the modeled peak with the least fold change was used for centering the data. Data were plotted using matplotlib (v.2.2.3).

\section{Statistical analysis}

1-way analysis of variance (ANOVA) was calculated for each unique peptide modified sequence (three independent biological replicates for six time points; F-statistic, degrees of freedom: 5, 12). Two-sided Dunnett's post-hoc test was used to determine whether specific time points were significantly different from zero. Adjusted p-values (q) were calculated from ANOVA p-values by applying the Benjamini-Hochberg method to correct for multiple comparisons.

\section{Fuzzy clustering}

Differentially-regulated peptides as determined by adjusted ANOVA were clustered using the package Mfuzz (v2.40) in R (v.3.4). The data were standardized so that each peptide had an average value of zero and a standard deviation of one across its time series. The fuzzifier parameter $m$ was estimated at 1.75 using the package's internal mestimate function. The number of clusters $c$ was determined by analyzing all $c$ from 2 to 20 and identifying no new temporal patterns beyond five clusters. Data were plotted using mfuzz.plot2. 


\section{PANTHER annotations}

Three of the five clusters identified using fuzzy c-means clustering had distinct temporal patterns and the remaining two clusters were combined for downstream analysis. Peptides were discretely assigned to one of these three representative clusters based on their highest cluster membership values. Peptides from each cluster were then represented by their respective genes only if all regulated peptides for each gene belonged to a single cluster. These gene-annotated clusters were analyzed for GO term statistical overrepresentation using PANTHER (pantherdb.org) and Reactome (Reactome.org). All annotations with a nominal p-value below 0.05 were included in table S2.

\section{Ingenuity Pathway Analysis}

Ingenuity Pathway Analysis (Qiagen) was completed for each individual time point. For each gene, the $\log _{2}$ fold change versus zero of the single peptide with the greatest change (absolute value) that passed Dunnett's post-hoc test was submitted for analysis. For peptides shared by multiple genes, only those with the highest annotation score (UniProt) were used. The reference set (background) was defined as the entire "User Dataset", which included all remaining, non-changing genes (with peptides that did not pass Dunnett's post-hoc test). Only direct relationships were considered and limited to "Experimentally Observed" confidence. All data sources, tissues, cell lines, and mutations were used, but only from the human species. To indicate EGF redox dynamics over $60 \mathrm{~min}$ for the various pathways presented in Fig. 4, gene products were first curated to each pathway to eliminate overlap. Then, the time course of $\log _{2}$ fold-changes for peptides belonging to curated gene products were added to the pathway heatmap if they were EGF-regulated at one or more timepoint.

\section{Bioinformatic analysis}

The amino acid position in the protein for each cysteine residue and site-specific annotation (such as active sites, disulfide type, topology and subcellular localization) was obtained using a Python script that searched the UniProtKB flat file (2018_07, 20380 entries). Protein domain and family annotation as well as the start and end position for all proteins was obtained from PFAM (v31) and used to create a domain specific FASTA database (BLAST v2.2.26). All non-cysteine containing domains and families were excluded and each identified site covered by a domain was annotated. Over-representation was identified by comparing all domains identified in our dataset versus all cysteine-containing domains in the human proteome and validated using a two-sided Fisher's exact test in R (v.3.3.3) (table S4). The combined charge at $\mathrm{pH} 7$ of the amino acids stretch (+/-2) surrounding each cysteine residue was calculated using the $\mathrm{R}$ package Peptides v2.4 and compared to the global charge distribution of all cysteine residues in the identified proteins. Only cysteine residues that can be theoretically covered by tryptic digestion were considered to prevent a bias for positively charged K/R residues and data analysis were performed using GraphPad Prism (v7.0b) by two-way ANOVA. Relative solvent accessibility (RSA) and secondary structure prediction was performed using NetSurfP-2 (67). An RSA above 25\% was considered surface accessible and secondary structures were assigned as helix, turn and beta-strand. 
Differentially alkylated peptides were only evaluated when all forms were identified (meaning 2-Ox and both 1-Ox forms). Pearson linear regression was calculated for the 1-Ox peptides across the time course as well the standard deviation at $60 \mathrm{~min}$.

\section{Calculating percent cysteine conservation and phylogenetic analysis}

The entire UniProt protein sequence was aligned with Clustal Omega (EMBL) followed by phylogenetic tree generation using Simple Phylogeny (EMBL), both using default parameters. Phylogenetic trees were visualized with iTOL (itol.embl.de) and annotated using domain information from UniProt and gene family information from the Human Gene Nomenclature Committee.

\section{Protein structure analysis}

Protein Data Bank (PDB) structures were visualized with Chimera (UCSF).

\section{Calculating percent of proteins significantly oxidized in each compartment}

Peptides were assigned to gene level as for IPA. Only proteins annotated to a single subcellular location in UniProt were analyzed because these are sentinels of specific compartments. The percent of significantly oxidized genes was calculated by taking the number of Dunnett positive proteins at each timepoint divided by the total number of sentinels assigned to each organelle.

\section{Molecular dynamics simulations}

Molecular dynamics simulations of GDP-bound KRAS were run with Gromacs 5.1.1 at 300 $\mathrm{K}$ using the AMBER03 force field with explicit TIP3P solvent (99-101). Simulation parameters for GDP are described elsewhere (102). Simulations were prepared by placing the starting structure (PDB ID: 4OBE) in a dodecahedron box that extends $1.0 \AA$ beyond the protein in any dimension. The system was then solvated (21490 atoms), and energy minimized with a steepest descents algorithm until the maximum force fell below 100 $\mathrm{kJ} / \mathrm{mol} / \mathrm{nm}$ using a step size of $0.01 \mathrm{~nm}$ and a cutoff distance of $1.2 \mathrm{~nm}$ for the neighbor list, Coulomb interactions, and van der Waals interactions. For production runs, all bonds were constrained with the LINCS algorithm and virtual sites were used to allow a 4 fs time step $(103,104)$. Cutoffs of $1.0 \mathrm{~nm}$ were used for the neighbor list, Coulomb interactions, and van der Waals interactions. The Verlet cutoff scheme was used for the neighbor list. The stochastic velocity rescaling ( $v$-rescale) $(100)$ thermostat was used to hold the temperature at $300 \mathrm{~K}$. Conformations were stored every $20 \mathrm{ps}$.

The FAST algorithm $(78,79)$ was used to enhance conformational sampling of states with large pocket openings. Pocket volumes were calculated using the LIGSITE algorithm, as implemented in enspara (105). FAST-pockets simulations were run for 25 rounds, with 10 simulations per round, where each simulation was $40 \mathrm{~ns}$ in length (10 $\mu$ s of aggregate simulation). In addition to ranking based on pocket volumes, a similarity penalty was included to promote conformational diversity in starting structures (106). An Markov state model (MSM) was built from the FAST simulation data using enspara (https://github.com/ bowman-lab/enspara). The state space was defined using backbone heavy atoms (atoms $\mathrm{C}$, $\mathrm{C}_{\mathrm{a}}, \mathrm{C}_{\beta}, \mathrm{N}, \mathrm{O}$ ), which was clustered with a $k$-centers algorithm based on root-mean-square 
deviation (RMSD) between conformations until every cluster center had a radius less than $1.2 \AA$ A. Following clustering, an MSM was built by row-normalizing the observed transition counts, at a lag-time of $2 \mathrm{~ns}$, with a small pseudo-count as a prior. Solvent accessible surface areas for each state in the MSM were calculated using MDTraj and were weighted based on their determined populations (107).

\section{Phylogenetic analysis of GTPases}

A multiple sequence alignment of all human small GTPases was performed with Clustal Omega (https://www.ebi.ac.uk/Tools/msa/clustalo/) and phylogenetic analysis was performed with Simple Phylogeny (https://www.ebi.ac.uk/Tools/phylogeny/ simple_phylogeny/). iTOL (https://itol.embl.de) was used to display phylogenetic tree and biochemical properties of each GTPase.

\section{Supplementary Material}

Refer to Web version on PubMed Central for supplementary material.

\section{Acknowledgments}

Funding: We acknowledge funding and support from R01 CA200893 (J.H), R21 CA138308 (J.H.), R21 CA179452 (J.H.), VR 2015-00656 (S.V.D.P), SSMF P17-0060 (S.V.D.P), the DRC at Washington University (Grant No. 5 P30 DK020579) and AB SCIEX. G.R.B. and M.I.Z. were funded by NIH GM124007 and NSF CAREER Award MCB-1552471. A.M. was supported by the T32GM007067-41 T32 training grant.

\section{References and Notes}

1. Bae YS, Kang SW, Seo MS, Baines IC, Tekle E, Chock PB, Rhee SG, Epidermal Growth Factor (EGF)-induced Generation of Hydrogen Peroxide, J. Biol. Chem 272, 217-221 (1997). [PubMed: 8995250]

2. Kwon J, Lee S-R, Yang K-S, Ahn Y, Kim YJ, Stadtman ER, Rhee SG, Reversible oxidation and inactivation of the tumor suppressor PTEN in cells stimulated with peptide growth factors, Proc. Natl. Acad. Sci 101, 16419-16424 (2004). [PubMed: 15534200]

3. Paulsen CE, Truong TH, Garcia FJ, Homann A, Gupta V, Leonard SE, Carroll KS, Peroxidedependent sulfenylation of the EGFR catalytic site enhances kinase activity, Nat. Chem. Biol 8, 57 64 (2012).

4. Winterbourn CC, Reconciling the chemistry and biology of reactive oxygen species, Nat. Chem. Biol 4, 278-286 (2008). [PubMed: 18421291]

5. Mahadev K, Zilbering A, Zhu L, Goldstein BJ, Insulin-stimulated Hydrogen Peroxide Reversibly Inhibits Protein-tyrosine Phosphatase 1B in Vivo and Enhances the Early Insulin Action Cascade, J. Biol. Chem 276, 21938-21942 (2001). [PubMed: 11297536]

6. Sundaresan M, Yu Z-X, Ferrans VJ, Irani K, Finkel T, Requirement for Generation of $\mathrm{H}(2) \mathrm{O}(2)$ for Platelet-Derived Growth Factor Signal Tran sduction, Science (80-.). 270, 296-299 (1995).

7. Handayaningsih A-E, Iguchi G, Fukuoka H, Nishizawa H, Takahashi M, Yamamoto M, Herningtyas E-H, Okimura Y, Kaji H, Chihara K, Seino S, Takahashi Y, Reactive Oxygen Species Play an Essential Role in IGF-I Signaling and IGF-I-Induced Myocyte Hypertrophy in C2C12 Myocytes, Endocrinology 152, 912-921 (2011). [PubMed: 21239445]

8. Schröder K, Helmcke I, Palfi K, Krause K-H, Busse R, Brandes RP, Nox1 Mediates Basic Fibroblast Growth Factor-Induced Migration of Vascular Smooth Muscle Cells, Arterioscler. Thromb. Vasc. Biol 27, 1736-1743 (2007). [PubMed: 17541028]

9. Yang LY, Ko WC, Lin CM, Lin JW, Wu JC, Lin CJ, Cheng HH, Shih CM, Antioxidant Nacetylcysteine blocks nerve growth factor-induced H 2O2/ERK signaling in PC12 cells, Ann. N. Y. Acad. Sci 1042, 325-337 (2005). [PubMed: 15965078] 
10. Thannickal VJ, Fanburg BL, Activation of an H 2 O 2 -generating NADH Oxidase in Human Lung Fibroblasts by Transforming Growth Factor $\beta 1$, J. Biol. Chem 270, 30334-30338 (1995). [PubMed: 8530457]

11. Meier B, Radeke HH, Selle S, Younes M, Sies H, Resch K, Habermehl GG, Human fibroblasts release reactive oxygen species in response to interleukin-1 or tumour necrosis factor-a, Biochem. J 263, 539-545 (1989). [PubMed: 2556998]

12. Lo YYC, Cruz TF, Involvement of Reactive Oxygen Species in Cytokine and Growth Factor Induction of c-fos Expression in Chondrocytes, J. Biol. Chem 270, 11727-11730 (1995). [PubMed: 7744816]

13. Kwon J, Qu C-K, Maeng J-S, Falahati R, Lee C, Williams MS, Receptor-stimulated oxidation of SHP-2 promotes T-cell adhesion through SLP-76-ADAP, EMBO J. 24, 2331-2341 (2005). [PubMed: 15933714]

14. Richards SM, Clark EA, BCR-induced superoxide negatively regulates B-cell proliferation and Tcell-independent type 2 Ab responses, Eur. J. Immunol 39, 3395-3403 (2009). [PubMed: 19877015]

15. Chen X, Abair TD, Ibanez MR, Su Y, Frey MR, Dise RS, Polk DB, Singh AB, Harris RC, Zent R, Pozzi A, Integrin 11 Controls Reactive Oxygen Species Synthesis by Negatively Regulating Epidermal Growth Factor Receptor-Mediated Rac Activation, Mol. Cell. Biol 27, 3313-3326 (2007). [PubMed: 17339338]

16. Griendling KK, Minieri CA, Ollerenshaw JD, Alexander RW, Angiotensin II stimulates NADH and NADPH oxidase activity in cultured vascular smooth muscle cells., Circ. Res 74, 1141-1148 (1994). [PubMed: 8187280]

17. Brown DI, Griendling KK, Nox proteins in signal transduction, Free Radic. Biol. Med 47, 12391253 (2009). [PubMed: 19628035]

18. Lee S-R, Kwon K-S, Kim S-R, Rhee SG, Reversible Inactivation of Protein-tyrosine Phosphatase 1B in A431 Cells Stimulated with Epidermal Growth Factor, J. Biol. Chem 273, 15366-15372 (1998). [PubMed: 9624118]

19. Haque A, Andersen JN, Salmeen A, Barford D, Tonks NK, Conformation-sensing antibodies stabilize the oxidized form of PTP1B and inhibit its phosphatase activity, Cell 147, 185-198 (2011). [PubMed: 21962515]

20. Dickinson BC, Chang CJ, Chemistry and biology of reactive oxygen species in signaling or stress responses, Nat. Chem. Biol 7, 504-11 (2011). [PubMed: 21769097]

21. Lim JM, Lee KS, Woo HA, Kang D, Rhee SG, Control of the pericentrosomal H 2 O 2 level by peroxiredoxin I is critical for mitotic progression, J. Cell Biol 210, 23-33 (2015). [PubMed: 26150388]

22. Markvicheva KN, Bogdanova EA, Staroverov DB, Lukyanov S, Belousov VV, in Methods in Molecular Biology, (Laboratory of Molecular Technologies for Biology and Medicine, Shemyakin-Ovchinnikov Institute of Bioorganic Chemistry, Russian Academy of Sciences, Moscow, Russia, 2008), vol. 476, pp. 76-83.

23. Woo HA, Yim SH, Shin DH, Kang D, Yu D-Y, Rhee SG, Inactivation of Peroxiredoxin I by Phosphorylation Allows Localized H2O2 Accumulation for Cell Signaling, Cell 140, 517-528 (2010). [PubMed: 20178744]

24. Yang J, Gupta V, Carroll KS, Liebler DC, Site-specific mapping and quantification of protein Ssulphenylation in cells, Nat. Commun 5, 4776 (2014). [PubMed: 25175731]

25. Held JM, Redox Systems Biology: Harnessing the Sentinels of the Cysteine Redoxome, Antioxid. Redox Signal, ars.2019.7725 (2019).

26. Feng X, Sun T, Bei Y, Ding S, Zheng W, Lu Y, Shen P, S-nitrosylation of ERK inhibits ERK phosphorylation and induces apoptosis, Sci. Rep 3, 1814 (2013). [PubMed: 23657295]

27. Östman A, Frijhoff J, Sandin Å, Böhmer F-D, Regulation of protein tyrosine phosphatases by reversible oxidation, J. Biochem 150, 345-356 (2011). [PubMed: 21856739]

28. Meng T-C, Buckley DA, Galic S, Tiganis T, Tonks NK, Regulation of Insulin Signaling through Reversible Oxidation of the Protein-tyrosine Phosphatases TC45 and PTP1B, J. Biol. Chem 279, 37716-37725 (2004). [PubMed: 15192089] 
29. Meng T-C, Fukada T, Tonks NK, Reversible Oxidation and Inactivation of Protein Tyrosine Phosphatases In Vivo, Mol. Cell 9, 387-399 (2002). [PubMed: 11864611]

30. Guo J, Gaffrey MJ, Su D, Liu T, Camp DG, Smith RD, Qian W-J, Resin-assisted enrichment of thiols as a general strategy for proteomic profiling of cysteine-based reversible modifications, Nat. Protoc 9, 64-75 (2014). [PubMed: 24336471]

31. Guo J, Nguyen AY, Dai Z, Su D, Gaffrey MJ, Moore RJ, Jacobs JM, Monroe ME, Smith RD, Koppenaal DW, Pakrasi HB, Qian W-J, Proteome-wide Light/Dark Modulation of Thiol Oxidation in Cyanobacteria Revealed by Quantitative Site-specific Redox Proteomics, Mol. Cell. Proteomics 13, 3270-3285 (2014). [PubMed: 25118246]

32. Alegre-Cebollada J, Kosuri P, Giganti D, Eckels E, Rivas-Pardo JA, Hamdani N, Warren CM, Solaro RJ, Linke WA, Fernández JM, S-Glutathionylation of Cryptic Cysteines Enhances Titin Elasticity by Blocking Protein Folding, Cell 156, 1235-1246 (2014). [PubMed: 24630725]

33. Held JM, Danielson SR, Behring JB, Atsriku C, Britton DJ, Puckett RL, Schilling B, Campisi J, Benz CC, Gibson BW, Targeted Quantitation of Site-Specific Cysteine Oxidation in Endogenous Proteins Using a Differential Alkylation and Multiple Reaction Monitoring Mass Spectrometry Approach, Mol. Cell. Proteomics 9, 1400-1410 (2010). [PubMed: 20233844]

34. Hansen RE, Winther JR, An introduction to methods for analyzing thiols and disulfides: Reactions, reagents, and practical considerations, Anal. Biochem 394, 147-158 (2009). [PubMed: 19664585]

35. Hansen RE, Roth D, Winther JR, Quantifying the global cellular thiol-disulfide status, Proc. Natl. Acad. Sci 106, 422-427 (2009). [PubMed: 19122143]

36. Danielson SR, Held JM, Oo M, Riley R, Gibson BW, Andersen JK, Quantitative Mapping of Reversible Mitochondrial Complex I Cysteine Oxidation in a Parkinson Disease Mouse Model, J. Biol. Chem 286, 7601-7608 (2011). [PubMed: 21196577]

37. Chang C, Chiang M, Toh EK-W, Chang C-F, Huang T, Molecular mechanism of oxidation-induced TDP-43 RRM1 aggregation and loss of function, FEBS Lett 587, 575-582 (2013). [PubMed: 23384725]

38. Chung HS, Murray CI, Van Eyk JE, A proteomics workflow for dual labeling biotin switch assay to detect and quantify protein S-nitroylation, Methods Mol. Biol 1747, 89-101 (2018). [PubMed: 29600453]

39. Sievers S, Dittmann S, Jordt T, Otto A, Hochgräfe F, Riedel K, Comprehensive Redox Profiling of the Thiol Proteome of Clostridium difficile, Mol. Cell. Proteomics 17, 1035-1046 (2018). [PubMed: 29496906]

40. Göransson U, Craik DJ, Disulfide Mapping of the Cyclotide Kalata B1, J. Biol. Chem 278, 4818848196 (2003). [PubMed: 12960160]

41. Gitler C, Zarmi B, Kalef E, Meller R, Zor U, Goldman R, Calcium-Dependent Oxidation of Thioredoxin during Cellular Growth Initiation, Biochem. Biophys. Res. Commun 290, 624-628 (2002). [PubMed: 11785944]

42. Li Y, Luo Z, Wu X, Zhu J, Yu K, Jin Y, Zhang Z, Zhao S, Zhou L, Proteomic Analyses of Cysteine Redox in High-Fat-Fed and Fasted Mouse Livers: Implications for Liver Metabolic Homeostasis, J. Proteome Res 17, 129-140 (2018). [PubMed: 29098862]

43. Olsen JV, Blagoev B, Gnad F, Macek B, Kumar C, Mortensen P, Mann M, Global, In Vivo, and Site-Specific Phosphorylation Dynamics in Signaling Networks, Cell 127, 635-648 (2006). [PubMed: 17081983]

44. Bowman GR, Geissler PL, Equilibrium fluctuations of a single folded protein reveal a multitude of potential cryptic allosteric sites, Proc. Natl. Acad. Sci 109, 11681-11686 (2012). [PubMed: 22753506]

45. Cuddihy SL, Winterbourn CC, Hampton MB, Assessment of Redox Changes to Hydrogen Peroxide-Sensitive Proteins During EGF Signaling, Antioxid. Redox Signal 15, 167-174 (2011). [PubMed: 21254838]

46. Zambuzzi WF, Granjeiro JM, Parikh K, Yuvaraj S, Peppelenbosch MP, Ferreira CV, Modulation of Src Activity by Low Molecular Weight Protein Tyrosine Phosphatase During Osteoblast Differentiation, Cell. Physiol. Biochem 22, 497-506 (2008). [PubMed: 19088431]

47. Noguchi M, Takata T, Kimura Y, Manno A, Murakami K, Koike M, Ohizumi H, Hori S, Kakizuka A, ATPase Activity of p97/Valosin-containing Protein Is Regulated by Oxidative Modification of 
the Evolutionally Conserved Cysteine 522 Residue in Walker A Motif, J. Biol. Chem 280, 4133241341 (2005). [PubMed: 16234241]

48. Yu L, Andruska N, Zheng X, Shapiro DJ, Anticipatory activation of the unfolded protein response by epidermal growth factor is required for immediate early gene expression and cell proliferation, Mol. Cell. Endocrinol 422, 31-41 (2016). [PubMed: 26551735]

49. Heppner DE, van der Vliet A, Redox-dependent regulation of epidermal growth factor receptor signaling, Redox Biol 8, 24-27 (2016). [PubMed: 26722841]

50. Treda C, Popeda M, Ksiazkiewicz M, Grzela DP, Walczak MP, Banaszczyk M, Peciak J, Stoczynska-Fidelus E, Rieske P, Buday L, Ed. EGFR Activation Leads to Cell Death Independent of PI3K/AKT/mTOR in an AD293 Cell Line, PLoS One 11, e0155230 (2016). [PubMed: 27153109]

51. Fan Q-W, Cheng C, Knight ZA, Haas-Kogan D, Stokoe D, James CD, McCormick F, Shokat KM, Weiss WA, EGFR Signals to mTOR Through PKC and Independently of Akt in Glioma, Sci. Signal 2, ra4-ra4 (2009). [PubMed: 19176518]

52. Er EE, Mendoza MC, Mackey AM, Rameh LE, Blenis J, AKT Facilitates EGFR Trafficking and Degradation by Phosphorylating and Activating PIKfyve, Sci. Signal 6, ra45-ra45 (2013). [PubMed: 23757022]

53. Rommel C, Differentiation Stage-Specific Inhibition of the Raf-MEK-ERK Pathway by Akt, Science (80-.). 286, 1738-1741 (1999).

54. Kim SF, Inducible Nitric Oxide Synthase Binds, S-Nitrosylates, and Activates Cyclooxygenase-2, Science (80-.). 310, 1966-1970 (2005).

55. Klomsiri C, Karplus PA, Poole LB, Cysteine-Based Redox Switches in Enzymes, Antioxid. Redox Signal 14, 1065-1077 (2011). [PubMed: 20799881]

56. Yigzaw Y, Poppleton HM, Sreejayan N, Hassid A, Patel TB, Protein-tyrosine Phosphatase-1B (PTP1B) Mediates the Anti-migratory Actions of Sprouty, J. Biol. Chem 278, 284-288 (2003). [PubMed: 12414790]

57. Motani K, Kushiyama H, Imamura R, Kinoshita T, Nishiuchi T, Suda T, Caspase-1 Protein Induces Apoptosis-associated Speck-like Protein Containing a Caspase Recruitment Domain (ASC)mediated Necrosis Independently of Its Catalytic Activity, J. Biol. Chem 286, 33963-33972 (2011). [PubMed: 21832064]

58. Bose K, Pop C, Feeney B, Clark AC, An Uncleavable Procaspase-3 Mutant Has a Lower Catalytic Efficiency but an Active Site Similar to That of Mature Caspase-3 †, Biochemistry 42, 1229812310 (2003). [PubMed: 14567691]

59. Rodriguez-Pascual F, Redondo-Horcajo M, Magan-Marchal N, Lagares D, Martinez-Ruiz A, Kleinert H, Lamas S, Glyceraldehyde-3-Phosphate Dehydrogenase Regulates Endothelin-1 Expression by a Novel, Redox-Sensitive Mechanism Involving mRNA Stability, Mol. Cell. Biol 28, 7139-7155 (2008). [PubMed: 18809573]

60. Juang Y-C, Landry M-C, Sanches M, Vittal V, Leung CCY, Ceccarelli DF, Mateo A-RF, Pruneda JN, Mao DYL, Szilard RK, Orlicky S, Munro M, Brzovic PS, Klevit RE, Sicheri F, Durocher D, OTUB1 Co-opts Lys48-Linked Ubiquitin Recognition to Suppress E2 Enzyme Function, Mol. Cell 45, 384-397 (2012). [PubMed: 22325355]

61. Schlotawa L, Wachs M, Bernhard O, Mayer FJ, Dierks T, Schmidt B, Radhakrishnan K, Recognition and ER Quality Control of Misfolded Formylglycine-Generating Enzyme by Protein Disulfide Isomerase, Cell Rep 24, 27-37.e4 (2018). [PubMed: 29972788]

62. Li FQ, Preferential MyoD homodimer formation demonstrated by a general method of dominant negative mutation employing fusion with a lysosomal protease, J. Cell Biol 135, 1043-1057 (1996). [PubMed: 8922385]

63. Egger S, Chaikuad A, Kavanagh KL, Oppermann U, Nidetzky B, Structure and Mechanism of Human UDP-glucose 6-Dehydrogenase, J. Biol. Chem 286, 23877-23887 (2011). [PubMed: 21502315]

64. Liu Y, Min W, Thioredoxin Promotes ASK1 Ubiquitination and Degradation to Inhibit ASK1Mediated Apoptosis in a Redox Activity-Independent Manner, Circ. Res 90, 1259-1266 (2002). [PubMed: 12089063] 
65. Street IP, Coffman HR, Poulter CD, Baker JA, Identification of Cys139 and Glu207 As Catalytically Important Groups in the Active Site of Isopentenyl Diphosphate:Dimethylallyl Diphosphate Isomerase, Biochemistry 33, 4212-4217 (1994). [PubMed: 7908830]

66. Weisner J, Gontla R, van der Westhuizen L, Oeck S, Ketzer J, Janning P, Richters A, Mühlenberg T, Fang Z, Taher A, Jendrossek V, Pelly SC, Bauer S, van Otterlo WAL, Rauh D, CovalentAllosteric Kinase Inhibitors, Angew. Chemie Int. Ed 54, 10313-10316 (2015).

67. Petersen B, Petersen T, Andersen P, Nielsen M, Lundegaard C, A generic method for assignment of reliability scores applied to solvent accessibility predictions, BMC Struct. Biol 9, 51 (2009). [PubMed: 19646261]

68. Oksvold MP, Huitfeldt HS, Langdon WY, Identification of 14-3-3 $\zeta$ as an EGF receptor interacting protein, FEBS Lett 569, 207-210 (2004). [PubMed: 15225635]

69. Pennington K, Chan T, Torres M, Andersen J, The dynamic and stress-adaptive signaling hub of 14-3-3: emerging mechanisms of regulation and context-dependent protein-protein interactions, Oncogene 37, 5587-5604 (2018). [PubMed: 29915393]

70. Jandova Z, Trosanova Z, Weisova V, Oostenbrink C, Hritz J, Free energy calculations on the stability of the 14-3-3 protein, Biochim. Biophys. Acta - Proteins Proteomics 1866, 442-450 (2018). [PubMed: 29203375]

71. Rossomando AJ, Payne DM, Weber MJ, Sturgill TW, Evidence that pp42, a major tyrosine kinase target protein, is a mitogen-activated serine/threonine protein kinase., Proc. Natl. Acad. Sci. U. S. A 86, 6940-3 (1989). [PubMed: 2550926]

72. Payne DM, Rossomando AJ, Martino P, Erickson AK, Her JH, Shabanowitz J, Hunt DF, Weber MJ, Sturgill TW, Identification of the regulatory phosphorylation sites in pp42/mitogen-activated protein kinase (MAP kinase)., EMBO J 10, 885-92 (1991). [PubMed: 1849075]

73. Goetz EM, Ghandi M, Treacy DJ, Wagle N, Garraway LA, ERK Mutations Confer Resistance to Mitogen-Activated Protein Kinase Pathway Inhibitors, Cancer Res 74, 7079-7089 (2014). [PubMed: 25320010]

74. Mitchell L, Hobbs GA, Aghajanian A, Campbell SL, Redox Regulation of Ras and Rho GTPases: Mechanism and Function, Antioxid. Redox Signal 18, 250-258 (2013). [PubMed: 22657737]

75. Kurokawa K, Itoh RE, Yoshizaki H, Nakamura YOT, Matsuda M, Coactivation of Rac1 and Cdc42 at lamellipodia and membrane ruffles induced by epidermal growth factor., Mol. Biol. Cell 15, 1003-10 (2004). [PubMed: 14699061]

76. Sikic K, Tomic S, Carugo O, Systematic Comparison of Crystal and NMR Protein Structures Deposited in the Protein Data Bank, Open Biochem. J 4, 83-95 (2010). [PubMed: 21293729]

77. Lim K-H, Ancrile BB, Kashatus DF, Counter CM, Tumour maintenance is mediated by eNOS, Nature 452, 646-649 (2008). [PubMed: 18344980]

78. Zimmerman MI, Bowman GR, FAST Conformational Searches by Balancing Exploration/ Exploitation Trade-Offs, J. Chem. Theory Comput 11, 5747-5757 (2015). [PubMed: 26588361]

79. Zimmerman MI, Bowman GR, in Methods in Enzymology, (2016), vol. 578, pp. 213-225. [PubMed: 27497168]

80. Porter JR, Moeder KE, Sibbald CA, Zimmerman MI, Hart KM, Greenberg MJ, Bowman GR, Cooperative Changes in Solvent Exposure Identify Cryptic Pockets, Switches, and Allosteric Coupling, Biophys. J 116, 818-830 (2019). [PubMed: 30744991]

81. Kolch W, Halasz M, Granovskaya M, Kholodenko BN, The dynamic control of signal transduction networks in cancer cells, Nat. Rev. Cancer 15, 515-527 (2015). [PubMed: 26289315]

82. Wu S-L, Kim J, Bandle RW, Liotta L, Petricoin E, Karger BL, Dynamic Profiling of the Posttranslational Modifications and Interaction Partners of Epidermal Growth Factor Receptor Signaling after Stimulation by Epidermal Growth Factor Using Extended Range Proteomic Analysis (ERPA), Mol. Cell. Proteomics 5, 1610-1627 (2006). [PubMed: 16799092]

83. Sharma K, D’Souza RCJ, Tyanova S, Schaab C, Wiśniewski JR, Cox J, Mann M, Ultradeep Human Phosphoproteome Reveals a Distinct Regulatory Nature of Tyr and Ser/Thr-Based Signaling, Cell Rep 8, 1583-1594 (2014). [PubMed: 25159151]

84. Tong J, Taylor P, Moran MF, Proteomic Analysis of the Epidermal Growth Factor Receptor (EGFR) Interactome and Post-translational Modifications Associated with Receptor Endocytosis 
in Response to EGF and Stress, Mol. Cell. Proteomics 13, 1644-1658 (2014). [PubMed: 24797263]

85. Zhang Y, Wolf-Yadlin A, Ross PL, Pappin DJ, Rush J, Lauffenburger DA, White FM, Timeresolved Mass Spectrometry of Tyrosine Phosphorylation Sites in the Epidermal Growth Factor Receptor Signaling Network Reveals Dynamic Modules, Mol. Cell. Proteomics 4, 1240-1250 (2005). [PubMed: 15951569]

86. Winterbourn CC, Reconciling the chemistry and biology of reactive oxygen species, Nat. Chem. Biol 4, 278-286 (2008). [PubMed: 18421291]

87. Johnson CP, Tang H-Y, Carag C, Speicher DW, Discher DE, Forced Unfolding of Proteins Within Cells, Science (80-. ) 317, 663-666 (2007).

88. Gould NS, Evans P, Martínez-Acedo P, Marino SM, Gladyshev VN, Carroll KS, Ischiropoulos H, Site-Specific Proteomic Mapping Identifies Selectively Modified Regulatory Cysteine Residues in Functionally Distinct Protein Networks, Chem. Biol 22, 965-975 (2015). [PubMed: 26165157]

89. Ermakova YG, Bilan DS, Matlashov ME, Mishina NM, Markvicheva KN, Subach OM, Subach FV, Bogeski I, Hoth M, Enikolopov G, Belousov VV, Red fluorescent genetically encoded indicator for intracellular hydrogen peroxide, Nat. Commun 5, 5222 (2014). [PubMed: 25330925]

90. Hopkins BL, Nadler M, Skoko JJ, Bertomeu T, Pelosi A, Shafaei PM, Levine K, Schempf A, Pennarun B, Yang B, Datta D, Bucur O, Ndebele K, Oesterreich S, Yang D, Rizzo MG, KhosraviFar R, Neumann CA, A Peroxidase Peroxiredoxin 1-Specific Redox Regulation of the Novel FOXO3 microRNA Target let-7, Antioxid. Redox Signal 28, 62-77 (2018). [PubMed: 28398822]

91. Bar-Peled L, Kemper EK, Suciu RM, Vinogradova EV, Backus KM, Horning BD, Paul TA, Ichu TA, Svensson RU, Olucha J, Chang MW, Kok BP, Zhu Z, Ihle NT, Dix MM, Jiang P, Hayward MM, Saez E, Shaw RJ, Cravatt BF, Chemical Proteomics Identifies Druggable Vulnerabilities in a Genetically Defined Cancer, Cell (2017), doi:10.1016/j.cell.2017.08.051.

92. Addona TA, Abbatiello SE, Schilling B, Skates SJ, Mani DR, Bunk DM, Spiegelman CH, Zimmerman LJ, Ham A-JL, Keshishian H, Hall SC, Allen S, Blackman RK, Borchers CH, Buck C, Cardasis HL, Cusack MP, Dodder NG, Gibson BW, Held JM, Hiltke T, Jackson A, Johansen EB, Kinsinger CR, Li J, Mesri M, Neubert TA, Niles RK, Pulsipher TC, Ransohoff D, Rodriguez H, Rudnick PA, Smith D, Tabb DL, Tegeler TJ, Variyath AM, Vega-Montoto LJ, Wahlander A, Waldemarson S, Wang M, Whiteaker JR, Zhao L, Anderson NL, Fisher SJ, Liebler DC, Paulovich AG, Regnier FE, Tempst P, Carr SA, Multi-site assessment of the precision and reproducibility of multiple reaction monitoring-based measurements of proteins in plasma, Nat. Biotechnol 27, 633641 (2009). [PubMed: 19561596]

93. Pike R, Ortiz-Zapater E, Lumicisi B, Santis G, Parsons M, KIF22 coordinates CAR and EGFR dynamics to promote cancer cell proliferation, Sci. Signal 11, eaaq1060 (2018). [PubMed: 29382784]

94. MacLean B, Tomazela DM, Shulman N, Chambers M, Finney GL, Frewen B, Kern R, Tabb DL, Liebler DC, MacCoss MJ, Skyline: an open source document editor for creating and analyzing targeted proteomics experiments, Bioinformatics 26, 966-968 (2010). [PubMed: 20147306]

95. Lim MY, O’Brien J, Paulo JA, Gygi SP, Improved Method for Determining Absolute Phosphorylation Stoichiometry Using Bayesian Statistics and Isobaric Labeling, J. Proteome Res 16, 4217-4226 (2017). [PubMed: 28985074]

96. Olsen JV, Vermeulen M, Santamaria A, Kumar C, Miller ML, Jensen LJ, Gnad F, Cox J, Jensen TS, Nigg EA, Brunak S, Mann M, Quantitative Phosphoproteomics Reveals Widespread Full Phosphorylation Site Occupancy During Mitosis, Sci. Signal 3, ra3-ra3 (2010). [PubMed: 20068231]

97. Weinert BT, Iesmantavicius V, Moustafa T, Schölz C, Wagner SA, Magnes C, Zechner R, Choudhary C, Acetylation dynamics and stoichiometry in S accharomyces cerevisiae, Mol. Syst. Biol 10, 716 (2014). [PubMed: 24489116]

98. Pascovici D, Wu JX, McKay MJ, Joseph C, Noor Z, Kamath K, Wu Y, Ranganathan S, Gupta V, Mirzaei M, Clinically relevant post-translational modification analyses-maturing workflows and bioinformatics tools, Int. J. Mol. Sci 20 (2019), doi:10.3390/ijms20010016.

99. Abraham MJ, Murtola T, Schulz R, Páll S, Smith JC, Hess B, Lindahl E, GROMACS: High performance molecular simulations through multi-level parallelism from laptops to supercomputers, SoftwareX 1-2, 19-25 (2015). 
100. Bussi G, Donadio D, Parrinello M, Canonical sampling through velocity rescaling, J. Chem. Phys 126, 014101 (2007). [PubMed: 17212484]

101. Duan Y, Wu C, Chowdhury S, Lee MC, Xiong G, Zhang W, Yang R, Cieplak P, Luo R, Lee T, Caldwell J, Wang J, Kollman P, A point-charge force field for molecular mechanics simulations of proteins based on condensed-phase quantum mechanical calculations, J. Comput. Chem 24, 1999-2012 (2003). [PubMed: 14531054]

102. Sun X, Singh S, Blumer KJ, Bowman GR, Simulation of spontaneous G protein activation reveals a new intermediate driving GDP unbinding, Elife 7 (2018), doi:10.7554/eLife.38465.

103. Feenstra KA, Hess B, Berendsen HJC, Improving efficiency of large time-scale molecular dynamics simulations of hydrogen-rich systems, J. Comput. Chem 20, 786-798 (1999).

104. Hess B, P-LINCS: A Parallel Linear Constraint Solver for Molecular Simulation, J. Chem. Theory Comput 4, 116-122 (2008). [PubMed: 26619985]

105. Porter JR, Zimmerman MI, Bowman GR, Enspara : Modeling molecular ensembles with scalable data structures and parallel computing, J. Chem. Phys 150, 044108 (2019). [PubMed: 30709308]

106. Zimmerman MI, Hart KM, Sibbald CA, Frederick TE, Jimah JR, Knoverek CR, Tolia NH, Bowman GR, Prediction of New Stabilizing Mutations Based on Mechanistic Insights from Markov State Models, ACS Cent. Sci 3, 1311-1321 (2017). [PubMed: 29296672]

107. McGibbon RT, Beauchamp KA, Harrigan MP, Klein C, Swails JM, Hernández CX, Schwantes CR, Wang L-P, Lane TJ, Pande VS, MDTraj: A Modern Open Library for the Analysis of Molecular Dynamics Trajectories, Biophys. J 109, 1528-1532 (2015). [PubMed: 26488642] 
A

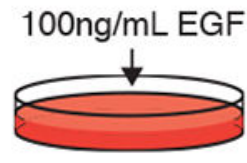

A431 cells

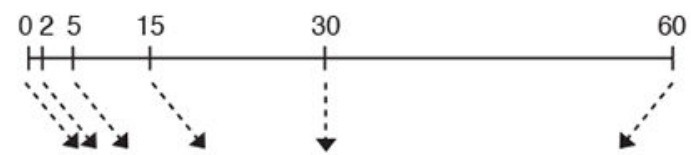

Lyse with SDS+NEM
$\mathbf{F}$
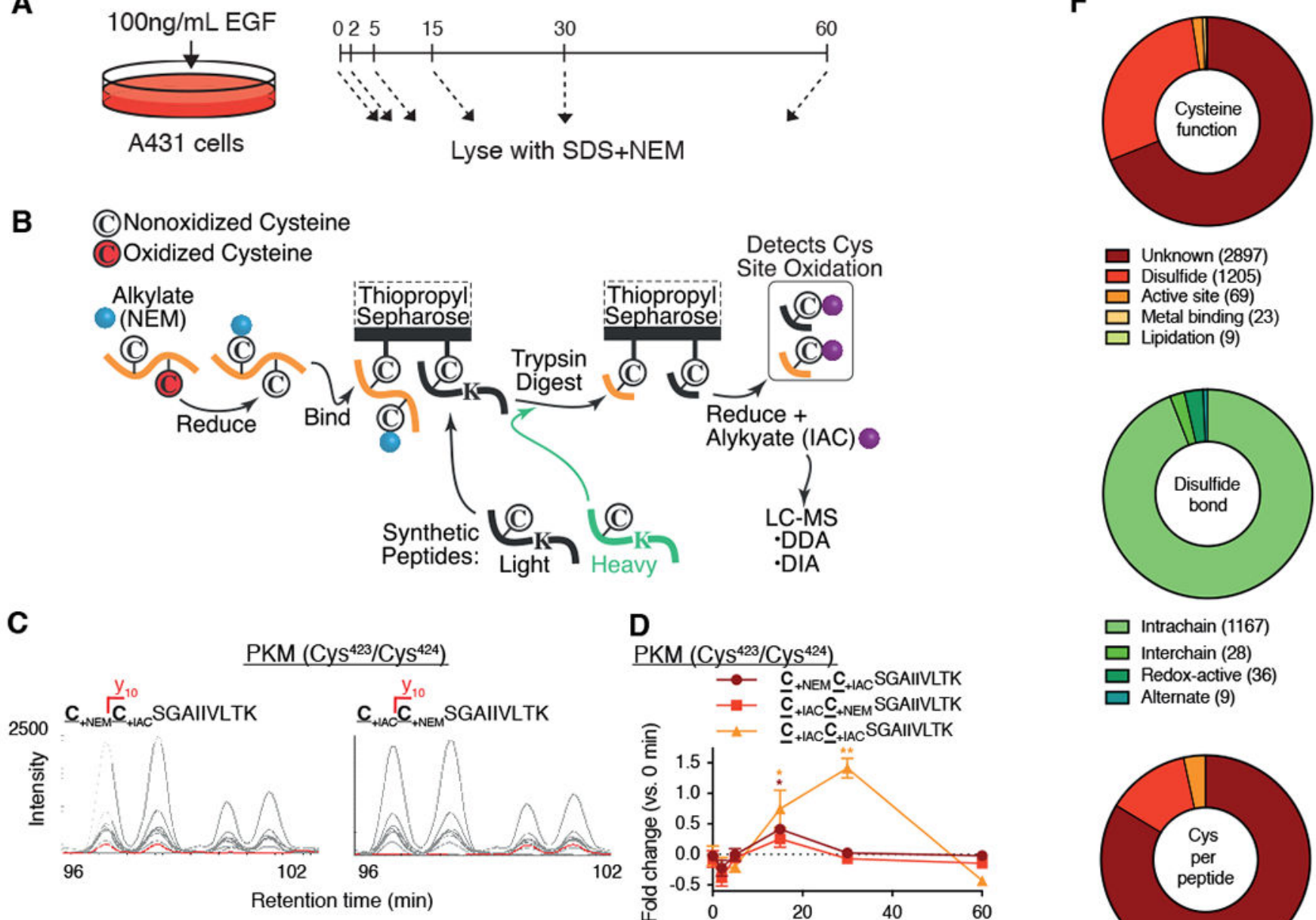

E

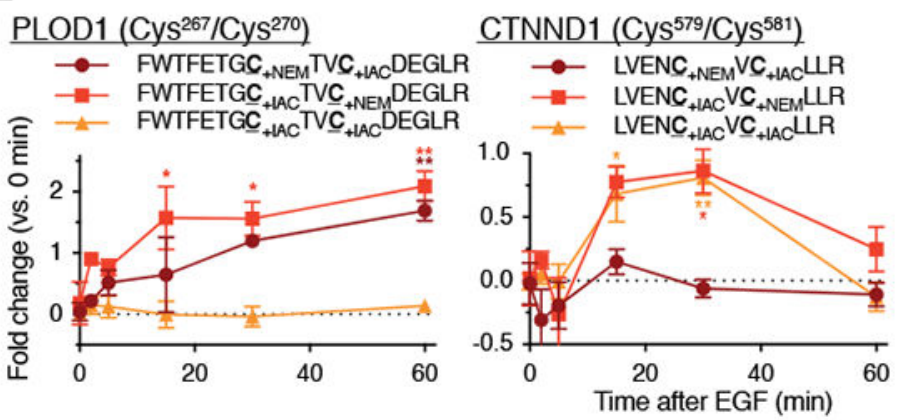

D

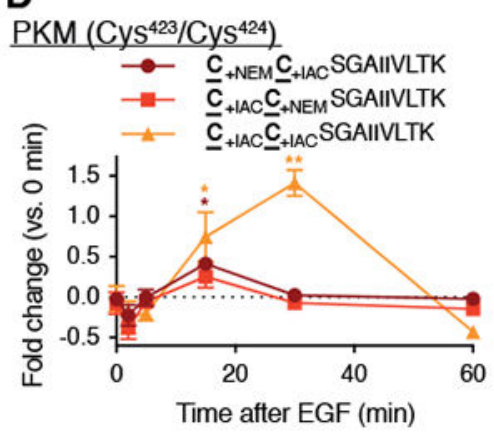

PKM (Cys $\left.{ }^{423} / \mathrm{Cys}^{424}\right)$

Detects Cys Site Oxidation

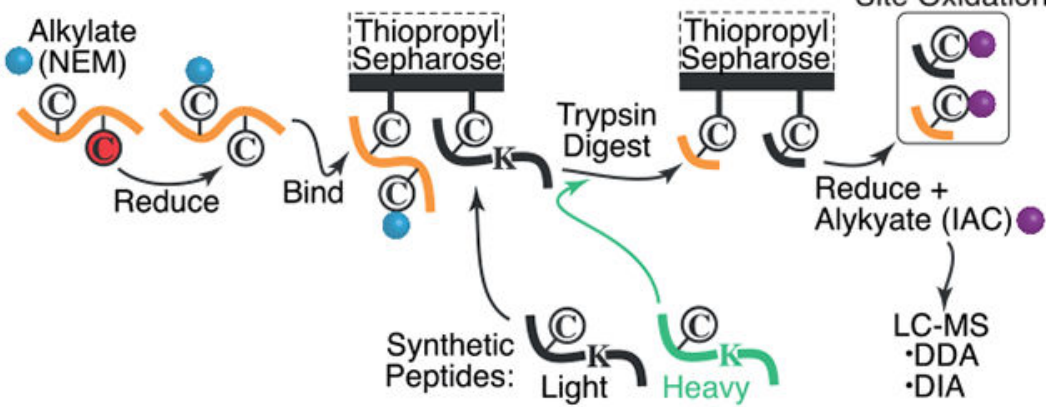

DLD (Cys $\left.{ }^{80} / \mathrm{Cys}^{85}\right)$ - NETLGGTC $_{+1 \mathrm{AC}} \mathrm{NNVGC}_{+\mathrm{NEM}}$ IPSK $\because$ NETLGGTC + IAC LNVGC + IACIPSK

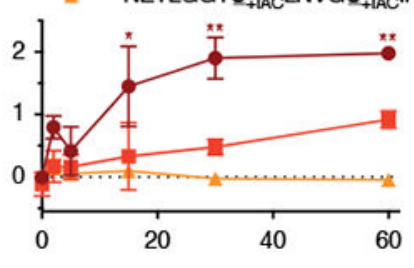
$\rightarrow-$ NETLGGTC $_{\text {NEM LNVGC }}$ HACIPS

Figure 1. The OxRAC workflow to globally profile cysteine oxidation and overview of results. A) Serum-starved A431 cells were left untreated $(0 \mathrm{~min})$ or stimulated with $100 \mathrm{ng} / \mathrm{mL}$ EGF for the times indicated prior to lysis. B) OxRAC workflow schematic in which free cysteine residues are trapped with NEM and oxidized thiols are enriched by thiopropyl sepharose resin and trypsin digested on-resin. The oxidized cysteine residues remain bound during washing, then are eluted by reduction and labeled with iodoacetamide (IAC) to differentiate oxidized (IAC-labeled) from non-oxidized (NEM-labeled) cysteine residues. Peptides are analyzed by data-dependent acquisition (DDA) to identify peptides and data-independent 
acquisition (DIA) mass spectrometry for quantification purposes based on high resolution MS2 scans. C) DIA-MS2 scans of the pyruvate kinase (PKM) peptide CCSGAIIVLTK. The site defining y 10 fragment ion (red line) between the two labeled cysteine residues confirms peak identity. (D and E) Time-dependent changes in the relative oxidation of PKM Cys ${ }^{423}$ and $\mathrm{Cys}^{424}$ (D), and of cysteine residues in procollagen-lysine 2-oxoglutarate 5-dioxygenase 1 (PLOD1), catenin delta-1 (CTNND1), and dihydrolipoyl dehydrogenase (DLD) in response to EGF stimulation. $* \mathrm{P}<0.05$, $* * \mathrm{P}<0.01$, based on one-way ANOVA with Dunnett's post-hoc test. Error bars are SEM for $\mathrm{N}=3$ independent biological replicates. Fold change is $\log _{2}$ transformed. F) Enumeration of the functional annotation, disulfide bond types, and number of cysteine residue per peptide in the dataset. 
A

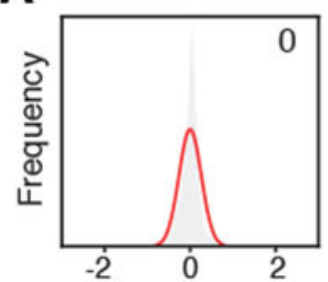

B
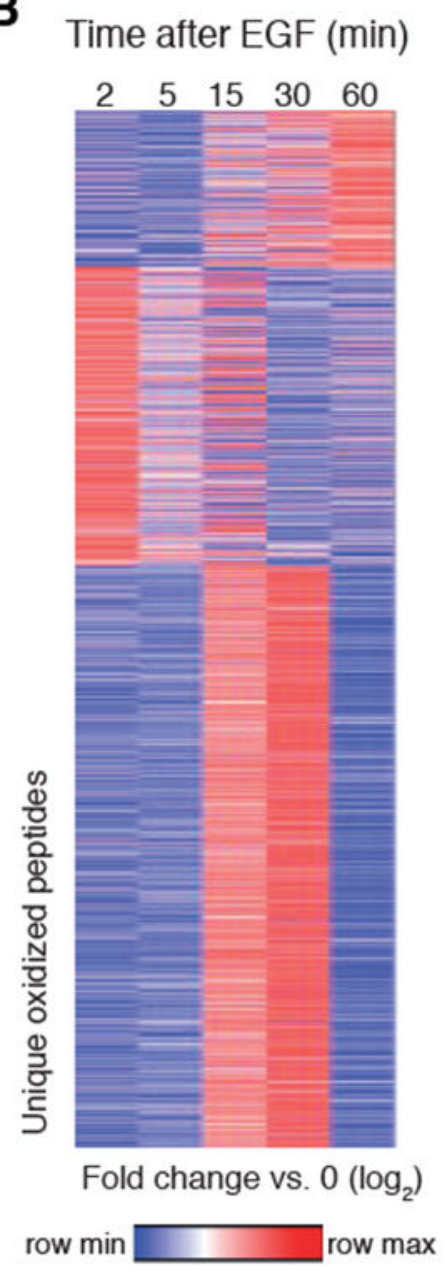

Time after EGF (min)

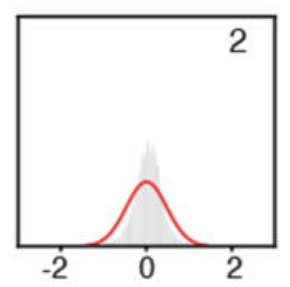

C

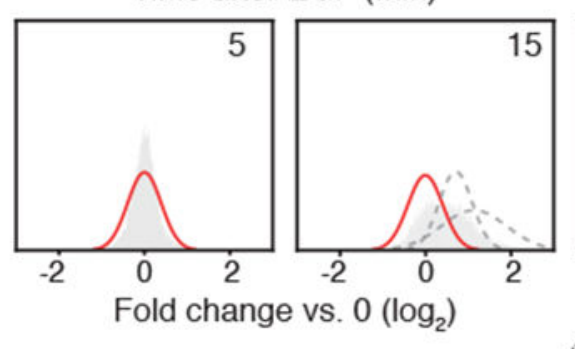

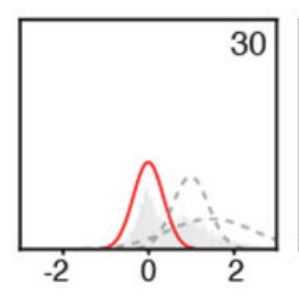

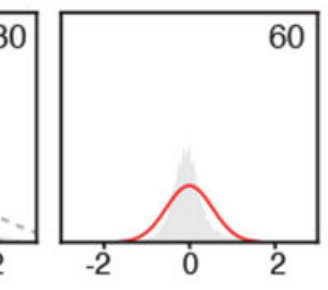

Figure 2. EGF-dependent regulation of cysteine redox networks cluster into three distinct temporal profiles associated with unique subcellular locations and biological processes. A) Average $\log _{2}$ fold change of all peptides compared to baseline $(n=3$ independent biological replicates). Lines indicate normal distributions and the red line indicates the fold change used for normalization. B) Heatmap of all significantly oxidized cysteine-containing peptides $(\mathrm{Q}<0.05$, ANOVA corrected by Benjamini-Hochberg) clustered by K-means (1 minus Pearson correlation, $\mathrm{K}=3$ ) of relative oxidation levels. C) Fuzzy c-means clustering of significantly oxidized peptides and selected Gene Ontology (GO) and Reactome annotations. P-values are from Panther. Fold change is $\log _{2}$ transformed. 
A

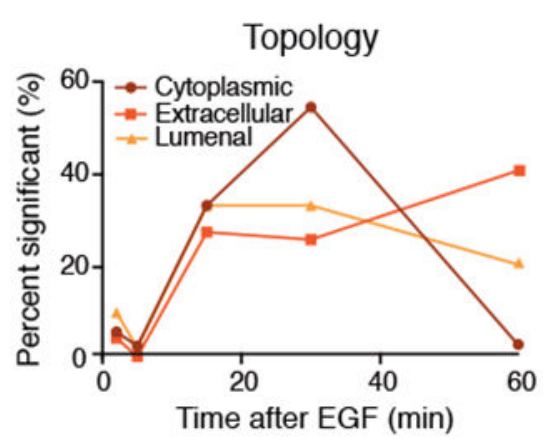

B

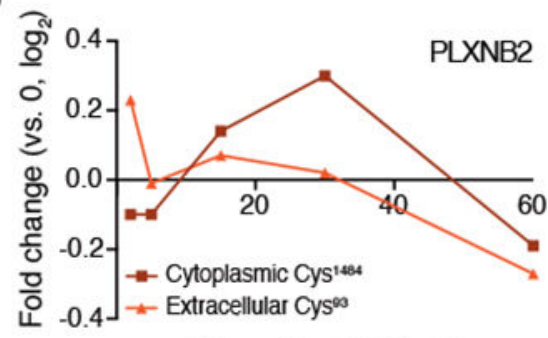

Time after EGF (min)

D

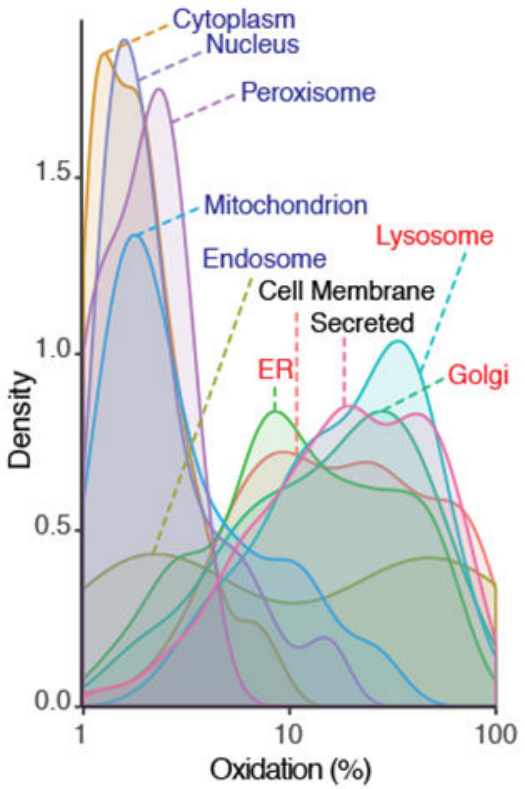

C

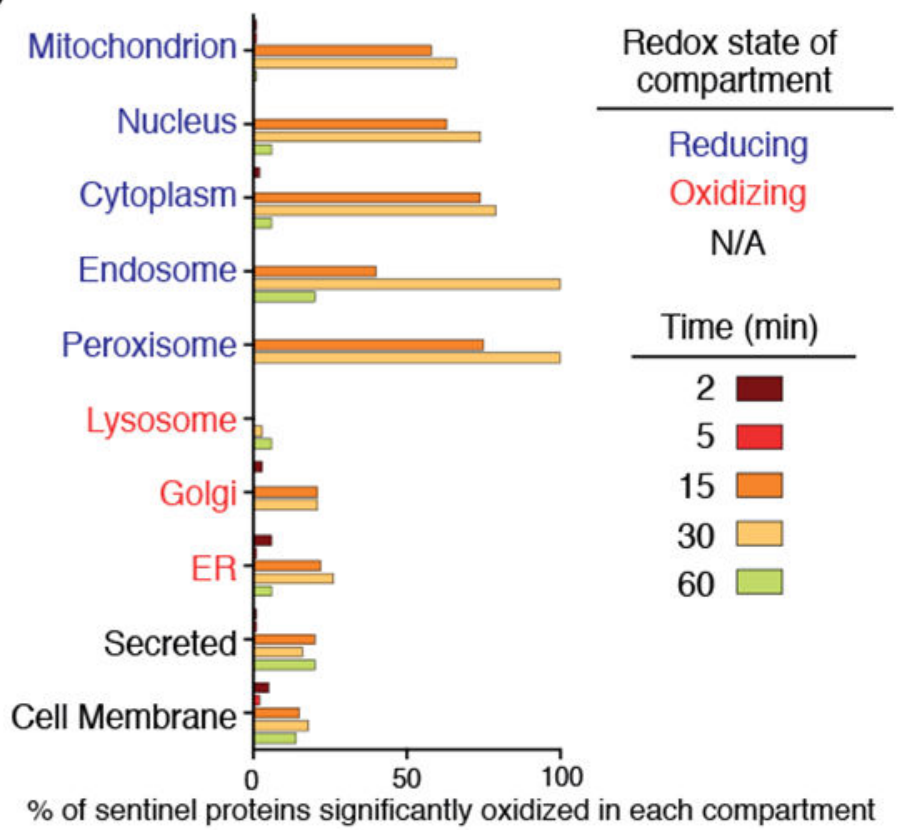

E

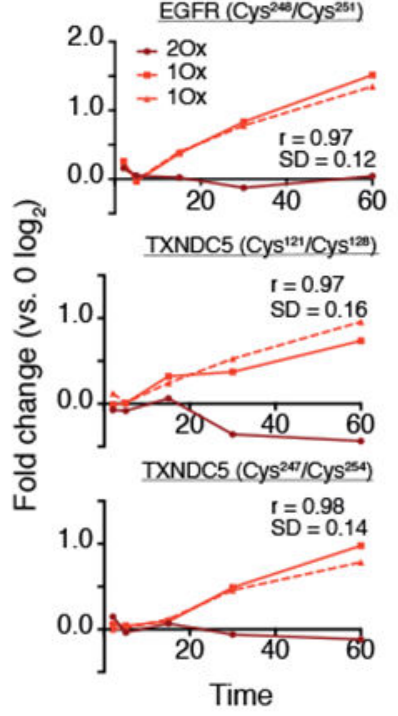

$\mathbf{F}$

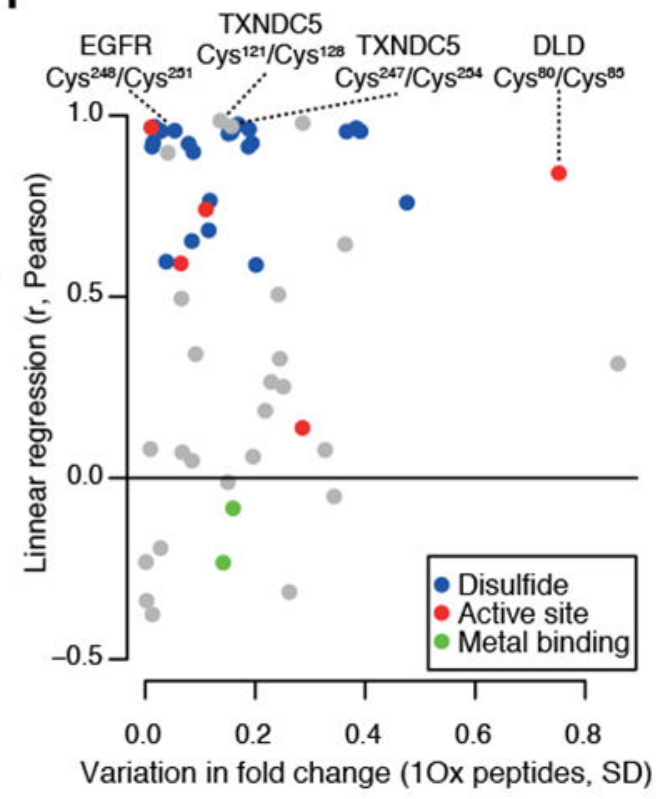

Figure 3. Cysteine residues in all major organelles are oxidized by EGF but location influences the temporal dynamics.

A) Membrane orientation of 182 modified sites on either the cytoplasmic, extracellular, or lumenal side presented as percentage significant over time in response to EGF. Significance per time point is based on $\mathrm{Q}<0.05$, ANOVA corrected by Benjamini-Hochberg. $\mathrm{N}=3$ independent biological replicates. B) Differential response over time of the extracellular and cytoplasmic side of the transmembrane protein Plexin-2B. C) The percentage of cysteine residues in 942 sentinel proteins detected by OxRAC and annotated to a single cellular 
compartment that have at least one cysteine residue significantly oxidized by EGF (ANOVA corrected by the Benjamini-Hochberg method). D) Estimated percent oxidation of all cysteine residues in sentinel proteins. E) Selected examples of differentially oxidized peptides containing 2 cysteine residuess. A disulfide bond in EGFR between $\mathrm{Cys}^{248}$ and $\mathrm{Cys}^{251}$ becomes reduced upon endocytosis in response to EGF. Examples of two previously unknown functional cysteine residues in TXNDC5 which are potentially disulfide linked.

1Ox and 2Ox indicate singly or doubly oxidized forms of the peptide, respectively. F) Linear regression ( $r$, Pearson) of the fold-change over time of the singly oxidized (1Ox) forms compared to the variation (standard deviation, $\mathrm{SD}$ ) between the two singly oxidized sites. Sites annotated as disulfide linked, active, or metal binding are indicated. Includes differentially oxidized sites identified in peptides spanning two cysteine residues. 

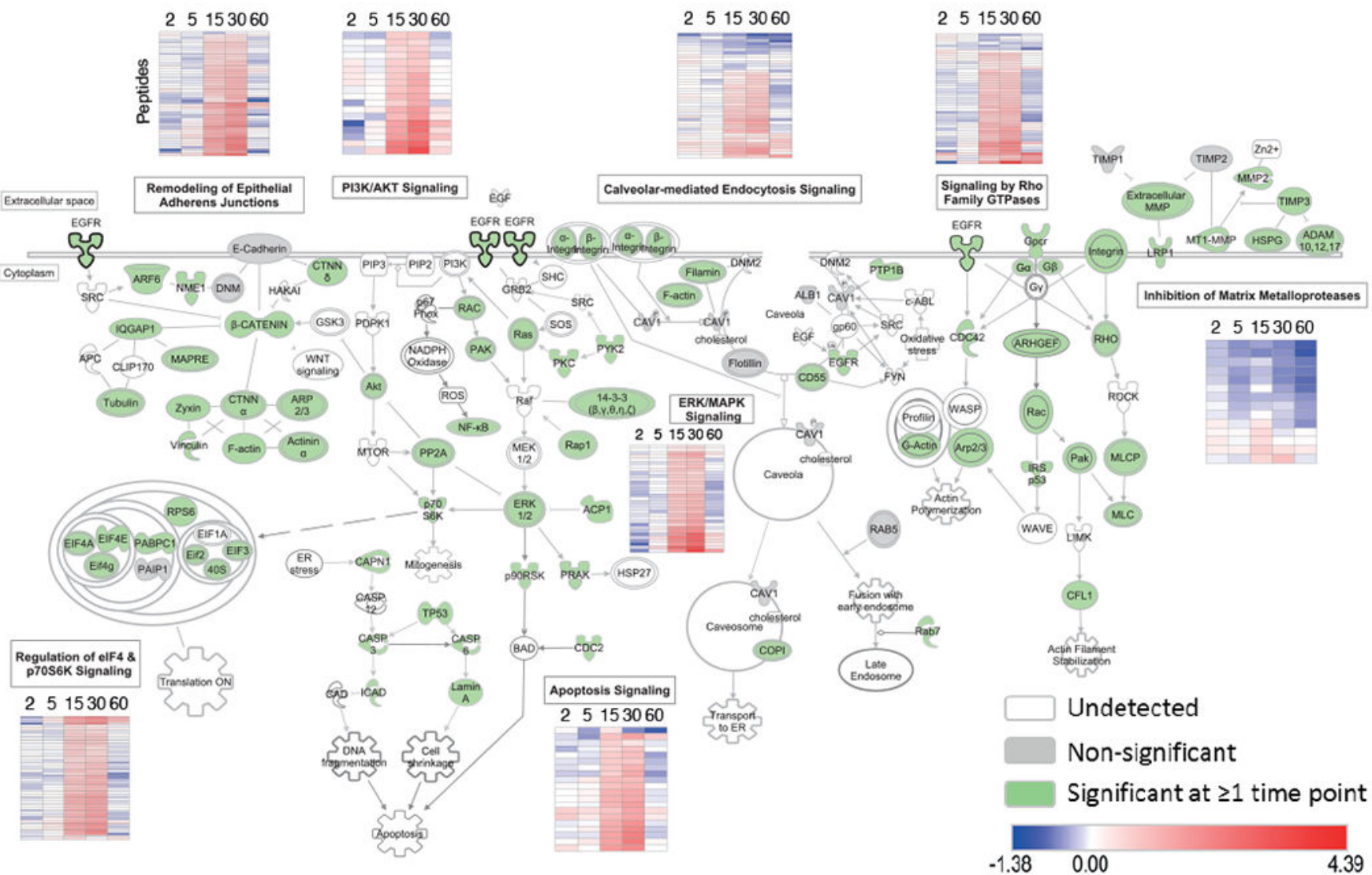

25153060
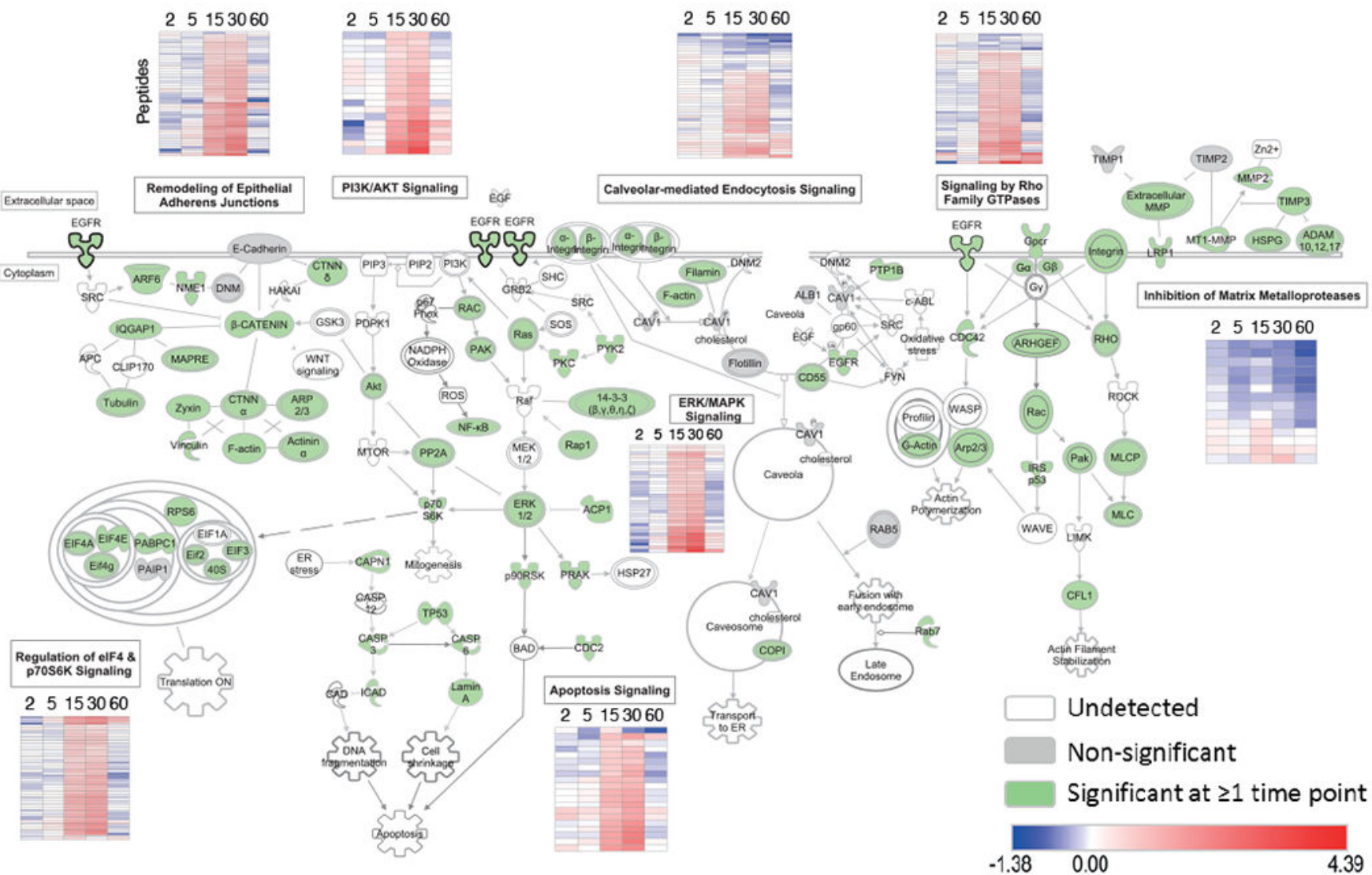

Figure 4. Synchronized redox regulation of cysteine residues throughout canonical EGF signaling pathways at 15 and 30 minutes.

Select enriched canonical pathways from IPA downstream of EGFR are pictured. All genes with a significantly regulated cysteine residue are colored green. $\mathrm{P}<0.05$ based one-way ANOVA with Dunnett's post-hoc test, $\mathrm{N}=3$ independent biological replicates. Proteins detected but not significantly oxidized by EGF are filled in grey and those undetected, but important for continuity of a pathway, were left unfilled. EGF redox dynamics over 60 minutes for significantly changing peptides in each pathway are represented in heatmaps. 
A

C
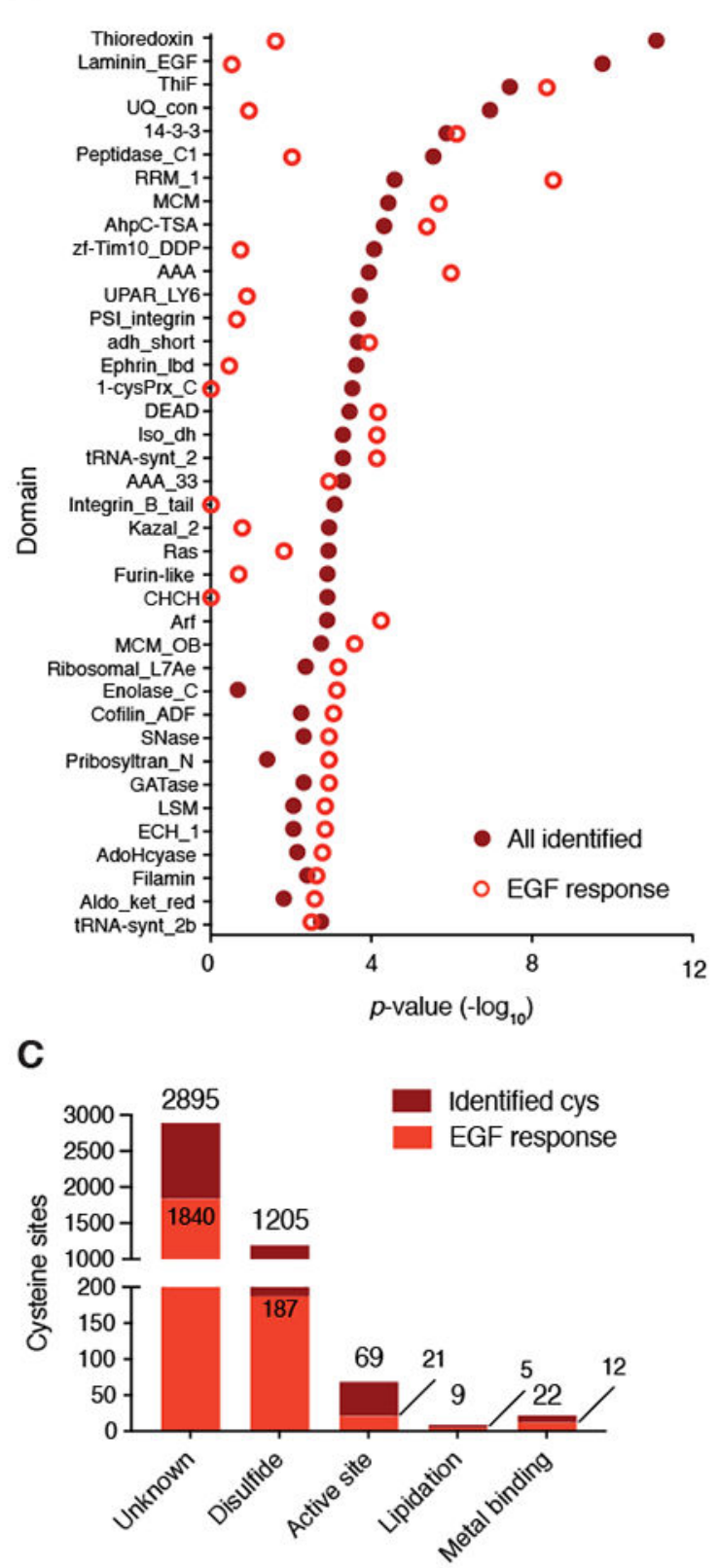

B

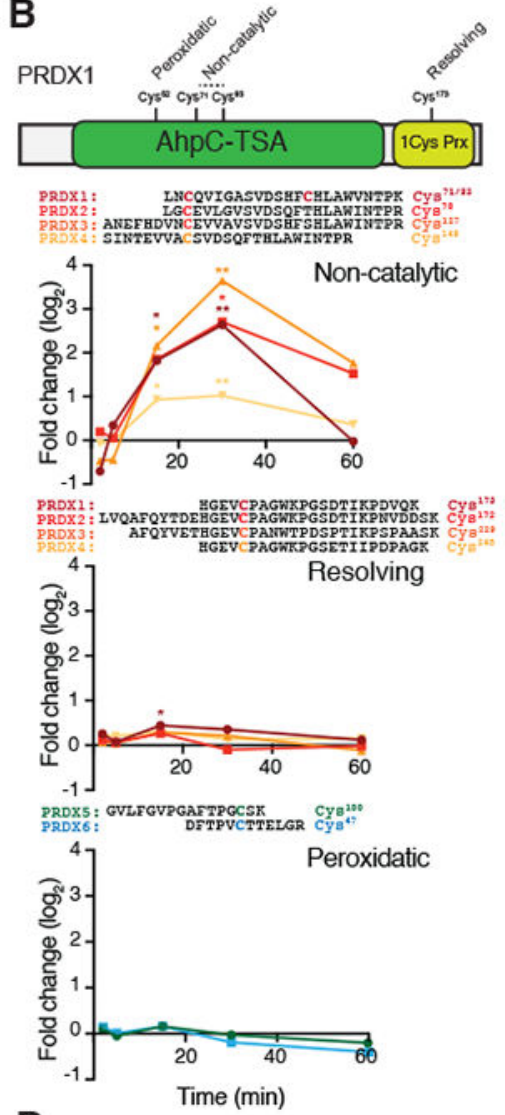

D

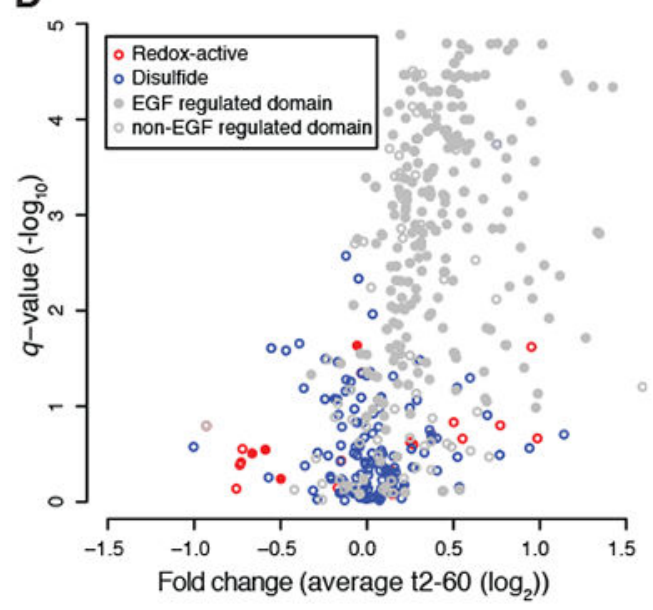

Figure 5. Protein domains redox regulated by EGF stimulation.

A) Enrichment of protein domains detected in the entire dataset 'all identified' or significantly oxidized by EGF, 'EGF response', as compared to all domains in the human proteome. P-values determined by two-tailed Fisher's exact test. B) Domain organization of PRDX1 and locations and function of its cysteine residues. The relative oxidation of the resolving, peroxidatic and non-catalytic cysteine residues in PRDXs over time in response to EGF stimulation. $* \mathrm{P}<0.05$, ** $\mathrm{P}<0.01$, based one-way ANOVA with Dunnett's post-hoc test. Error bars are SEM for $\mathrm{N}=3$ independent biological replicates. C) Functional annotation 
of all cysteine residues detected compared to those significantly regulated in response to EGF. D) The average ratio of all peptides assigned to the most enriched domains compared to their overall significance (q), overlaid with functional annotation when available. Closed circles: enriched sites in response to EGF, open circles: not enriched in response to EGF. Adjusted p-values (q) were calculated from ANOVA results by applying the BenjaminiHochberg method to correct for multiple comparisons. 
A

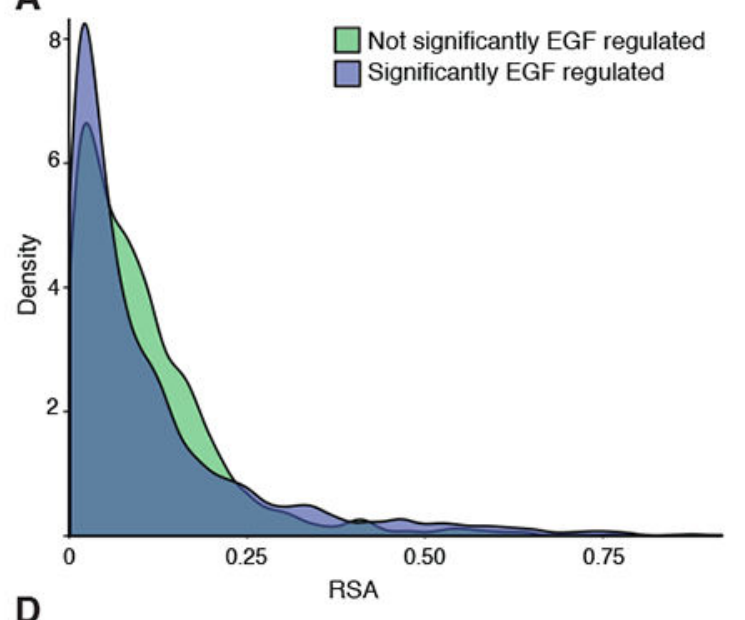

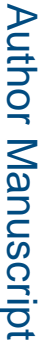

14-3-3 Protein family

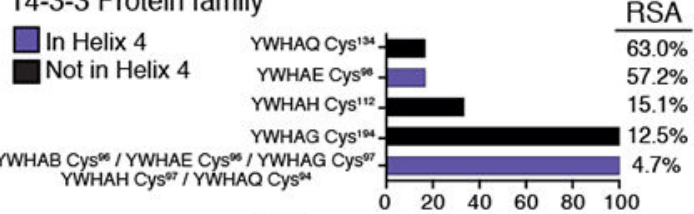

$\%$ Cys conservation across $14-3-3$ proteins

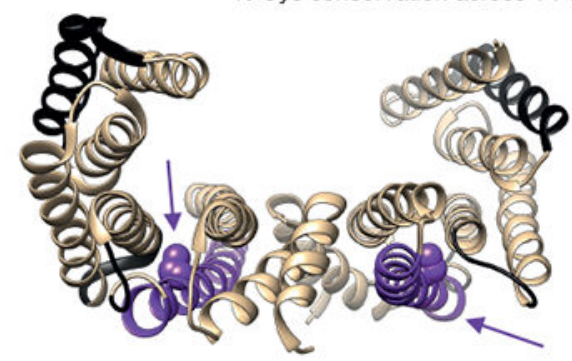

H KRAS: Crystal Structure KRAS: MD Simulation
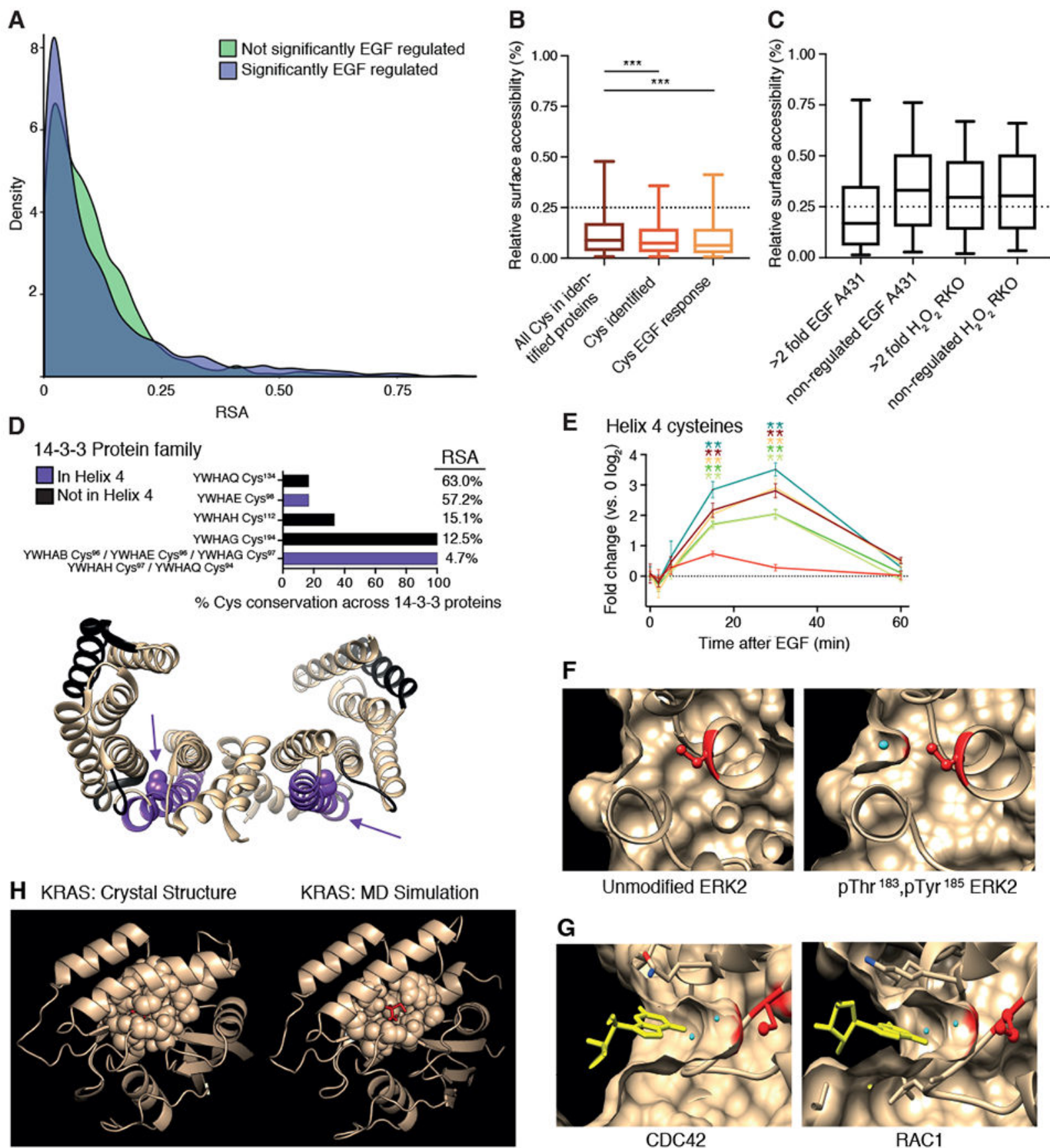

E Helix 4 cysteines
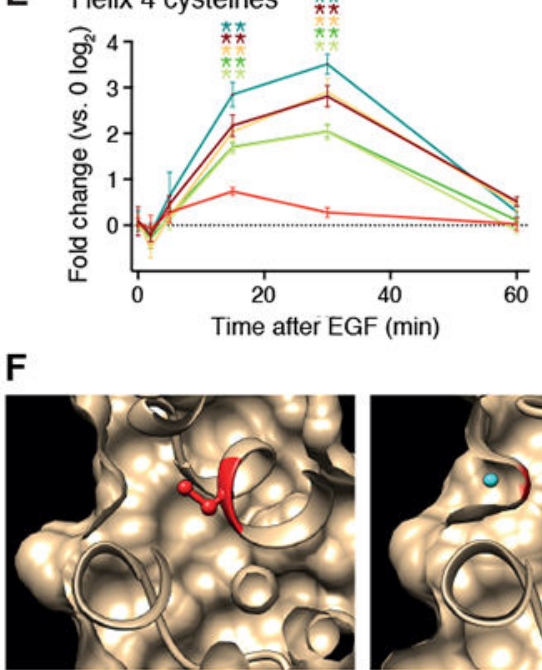

Unmodified ERK2

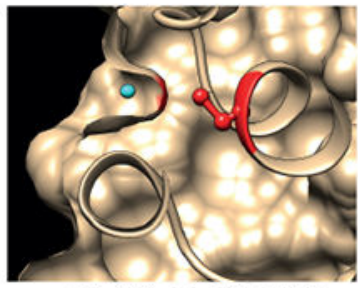

pThr ${ }^{183}$, pTyr ${ }^{185}$ ERK2

G

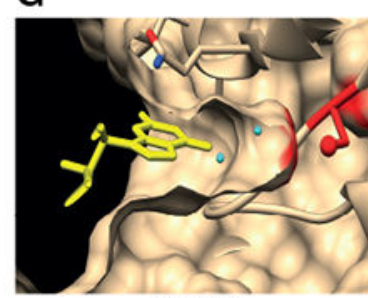

CDC42

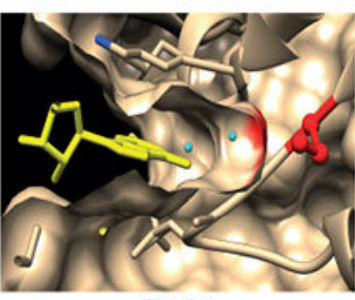

RAC1

Figure 6. EGF-dependent redox regulation of buried cysteine residues in 14-3-3, small GTPase proteins, and ERK2.

A) Density plot of relative solvent accessibility (RSA) that compares cysteine residues significantly and not regulated by EGF. B) RSA for all cysteine residues in proteins identified compared to all cysteine residues specifically quantified and those significantly regulated. Sites $>0.25$ are considered solvent accessible. $* \mathrm{p}<0.05, * * * \mathrm{p}<0.001$ by oneway ANOVA. For the box-whisker plot: center line is median, limits are upper and lower quartiles, and whiskers are 5 and 95 percentiles. C) RSA prediction for sulfenated cysteine 
residues in (24). D) Amino acid sequence conservation of the cysteine residues identified in 14-3-3 proteins. Structure of dimerized 14-3-3 sigma (PDB: 4DAU) with helix 4 shown in purple and locations of the remaining oxidized cysteine residues shown in black. Purple arrows point to the conserved cysteine residue in Helix 4, represented as a sphere. Relative surface accessibility (RSA) is indicated for each cysteine site or the average across 14-3-3 family members. E) Time-dependent changes in the oxidation of 14-3-3 cysteine residue. *P $<0.05, * * \mathrm{P}<0.01$, based one-way ANOVA with Dunnett's post-hoc test. Error bars are SEM for $\mathrm{N}=3$ independent biological replicates. F) Unmodified and phosphorylated ( $\mathrm{Thr}^{183}$ and $\mathrm{Tyr}^{185}$ ) ERK2 crystal structures (PDB: 1ERK and 2ERK, respectively) with Cys ${ }^{65}$

highlighted in red and solvent as a cyan sphere. G) Crystal structures of the GTP binding pocket in CDC42 (PDBID: 5CJP) and Rac1 (PDBID: 5033 GTP analogue). Cys ${ }^{157}$ is highlighted in red. Yellow structure is the bound GTP nucleotide analogue. Cyan spheres indicate solvent molecules. H) Representative crystal structure of KRAS (left, PDB: 5VQ2) in which $\mathrm{Cys}^{80}$ (red) is solvent inaccessible as well as a representative structure from MD simulations of KRAS (right) in which $\mathrm{Cys}^{80}$ is solvent accessible. Amino acid side chains within 7 angstroms of $\mathrm{Cys}^{80}$ are shown as spheres, and $\mathrm{Cys}^{80}$ is shown in red as a ball-andstick. 